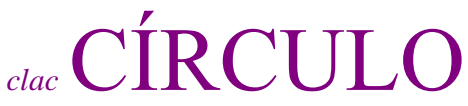 \\ de \\ lingüistica
aplicada a la \\ comunica
}

$60 / 2014$

\section{LOS VERBOS COPULATIVOS Y PSEUDOCOPULATIVOS \\ EN LA TRADUCCIÓN DEL ITALIANO AL ESPAÑOL}

\author{
Miquel Edo Julià \\ Universitat Autònoma de Barcelona \\ miquel edo en uab cat
}

\section{Resumen}

Las disimetrías que ofrecen italiano y español en el empleo de los verbos copulativos y, más específicamente, en su elipsis obligan al traductor a adoptar estrategias destinadas a evitar abusos y repeticiones cacofónicas de los mismos. Por otro lado, un estudio de los pseudocopulativos en ambas lenguas da como resultado un comportamiento sensiblemente distinto en la desemantización y frecuencia de uso de cada uno de ellos. Todo ello sugiere la utilidad de una serie de indicaciones que, caso por caso, proporcionen la agilidad necesaria para conmutar un pseudocopulativo por otro o para reemplazar pseudocopulativo por cópula o viceversa.

Palabras clave: verbos copulativos, verbos pseudocopulativos modales, verbos pseudocopulativos aspectuales, lingüística contrastiva italiano-español.

Edo, Miquel. 2014.

Los verbos copulativos y pseudocopulativos en la traducción del italiano al español.

Círculo de Lingüística Aplicada a la Comunicación 60, 62-121.

http://www.ucm.es/info/circulo/no60/edo.pdf

http://revistas.ucm.es/index.php/CLAC

DOI: http://dx.doi.org/10.5209/rev_CLAC.2014.v60.47444

(C) 2014 Miquel Edo

CÍRCULO de Lingüística Aplicada a la Comunicación (clac)

Universidad Complutense de Madrid. ISSN 1576-4737. http://www.ucm.es/info/circulo 


\begin{abstract}
Translating copulas and pseudo-copulas from Italian to Spanish. The lack of symmetry in the use, and in particular the deletion, of copulas between Italian and Spanish requires translators to adopt strategies to avoid over-use or cacophonies of these common verbs. Similarly, if we analyse pseudo-copulas in both languages we can see that there are slight differences in the desemanticization and frequency of use of each pseudo-copula. For this reason it is important to propose guidelines which, case by case, provide translators with the necessary skills to switch one pseudo-copula for another, substitute pseudo-copulas for copulas, or vice versa.
\end{abstract}

Key words: copulas, modal pseudo-copulas, aspectual pseudo-copulas, contrastive linguistics Italian-Spanish.

Índice

1. Elipsis de essere, 63

2. Rappresentare, sembrare, parere, constituir, mostrarse, dimostrarsi, 76

3. Apparire, resultar, 89

4. Diventare, quedar(se), 95

5. Revelarse, scoprirsi, 103

6. Conclusiones, 106

Bibliografía, 109

Fuentes de los ejemplos, 112

1. Elipsis de essere

1.1. Funciones divergentes de la cópula en italiano y español

El español y el italiano comparten la preocupación retórica por no caer, sobre todo en registros formales y escritos, en un abuso del verbo ser / essere, considerado un recurso demasiado fácil o pobre. En la traducción, además, y no sólo entre estas dos lenguas, el 
peligro de dicho sobrexceso suele aumentar, dado que la frecuente inexistencia o inadecuación de soluciones literales invita a menudo a resolver una voz única mediante frases. En el caso concreto de la traducción del italiano al castellano los estudios o manuales de contrastiva generalmente ahondan poco en esta estrategia, que -en cambio- en la praxis es ampliamente explotada por los traductores, por ejemplo para conjunciones y adverbios tan frecuentes como los siguientes: "así es", "y es que", "lo cierto es que" o "lo que pasa es que" para "infatti"; "así es como" o "éste -a es" para "ecco"; "es que" para el "ma" enfático ("Ma non posso" > "Es que no puedo") o para el "mai" de las frases interrogativas y condicionales ("come mai" > "cómo es que", "se mai" > "si es que"); "si es oportuno" y "si es posible" para "eventualmente" y "possibilmente"; “es más" para "anzi”, o el subjuntivo "sea” pospuesto al adverbio para la desinencia -unque (“dovunque" > "donde sea", “dondequiera que sea"). Se efectúan, asimismo, con regularidad reforzamientos sintácticos del tipo "así es como" para “così", "es lo que" para el propio "così" o para demostrativos ("così volevo" > "(eso) es lo que quería"), o "que es" para adverbios y pronombres relativos ("lavoro fino alle tre, quando mi fermo per pranzare" > "que es cuando hago una pausa para comer").

Otros tres fenómenos favorecen la presencia de ser en castellano. Ante todo, la mayor proclividad, respecto al italiano, a sustituir el predicado nominal por el pronombre neutro lo:

Anche la seconda moglie, Teresa Borri, è fedele esecutrice, come già nel caso dei dittonghi, della censura famigliare [es una fiel ejecutora, como ya lo había sido en el caso de los diptongos] (Albertocchi 1996: 196)

El segundo: cierta proliferación del gerundio siendo, utilizado en construcciones en las que difícilmente se adoptará en italiano. Varios estudios ya han puesto de relieve un mayor radio de acción de la perífrasis estar + gerundio respecto a su correspondiente italiana (Sánchez Montero 1993: 88-104; Ross 2006: 455). No han pasado desapercibidos ni la facultad del español, no compartida por el italiano, de conjugar el auxiliar en tiempos compuestos ("He estado viendo la televisión toda la noche", Bini y Guil 2002: 89-90), ni los fuertes reparos que oponen tanto la normativa como el uso, en Italia, a "stare essendo" (“está siendo inteligente”, “está siendo investigado", Musto y 
Ripa 2008: 412-413; Garosi 2010: 129), pero la versatilidad del gerundio de ser también se pone de manifiesto más allá de dichas perífrasis:

Egli ci permette di ricostruire la sua vita prima della sua impresa italica, informandoci che conseguì il trono da bambino, e che ciò lo obbligò a lunghe lotte per preservare il potere: [alcanzó el trono siendo un niño] (Frediani 2012 [2002]: 278)

El tercero: el gusto también ligeramente superior que muestra el castellano por la forma de infinitivo, ser, en parte — volveremos sobre ello más adelante- por su alta productividad en el sector de las perífrasis y su alto grado de aceptabilidad como núcleo de la subordinada sustantiva de un pseudocopulativo ("parece ser que", "no deja de ser", "resultó ser", “demostró ser", "ha revelado ser"), en parte como reverso de la fuerte propensión del italiano a la nominalización. En muchos casos, en efecto, es la poca naturalidad de algunos sustantivos deverbales o deadjetivales, o del sintagma del que forman parte, lo que empuja a traducir con una copulativa o una pasiva. Que se efectúe esta modificación o se respete la sintaxis original dependerá a menudo de las preferencias personales de cada traductor, pero también entran en juego factores relacionados con el registro. El mayor peso de la sintaxis nominal en italiano se vincula a un listón retórico que se sitúa casi siempre, en los distintos niveles, algo más arriba que en castellano. En el último de los siguientes ejemplos, cabría la posibilidad, en principio, de traducir "te han reñido ... por tu falta de atención", pero tal sintagma preposicional no parece demasiado verosímil en boca de una adolescente que está hablando con su mejor amiga. En contrapartida, la pasiva proporciona cierta dosis de elegancia, como se puede apreciar si se comparan, en la segunda cita, las dos propuestas que facilitamos:

Tale giudizio, data la fama e l'autorità dello scrittore, e forse anche la sua eccezionale unicità, ha un grande successo presso i contemporanei [Esta valoración, dada la fama y autoridad de quien la escribe, y quizás también por el hecho de ser tan excepcional y única, / y quizás también por ser tan excepcional y única, / y quizás también por su excepcionalidad,] (Albertocchi 2000: 186)

Tuttavia i manoscritti originali rimasero nascosti nelle biblioteche e negli archivi romani della Compagnia di Gesù fino alla loro scoperta da parte del geografo 
gesuita olandese Cornelis Wessels che ne fornì notizia nel 1924 [hasta ser descubiertos por el geógrafo / hasta que los descubrió el geógrafo] (Bargiacchi 2011:14)

Alle 13:00, uscite da scuola Sana e Fuka fecero insieme la strada per arrivare alle rispettive case... - Oggi avevi la testa fra le nuvole! Sei stata richiamata un sacco di volte per la tua disattenzione... - Già... - Pensavi a lui non è vero? [Te han llamado la atención un montón de veces por no estar atenta...] (G4bry 2007: cap. 12)

La sintaxis contrastiva pone también sobre la mesa, desde luego, disimetrías que conducen, en la dirección contraria, a la desaparición, en el texto meta, de ocurrencias de essere presentes en el original. Algunas se cuentan entre las que más tempranamente adquiere el estudiante de lengua italiana dentro de su proceso de aprendizaje: a) la función de essere como verbo auxiliar en tiempos compuestos y el mayor uso de estos tiempos, ya sea por el mayor rigor con que se aplica la consecutio temporum ("quando sarò arrivato" > "cuando llegue", Carrera Díaz 1984: 212-213), ya sea —más específicamente - por la fuerza del pretérito perfecto frente al indefinido ("sono venuto ieri" > "vine ayer"); b) la parte del radio de acción de essere que es cedida en español al otro verbo copulativo, estar ("sono stanco" > "estoy cansado"), o c) el gusto por la voz pasiva, cuyo auxiliar es a menudo omitido, pero — claro está — no siempre:

Eri attratto da quel mio travestimento e dalla mia spavalderia. E io ero attratta da te, ma così impaurita. [Te atraían ... Y a mí me atraías tú / Te sentías atraído por ... Y yo me sentía atraída por ti] (Cibrario 2008: 58)

Como es bien sabido, la variante pronominalizada esserci reparte sus equivalencias básicamente entre haber y estar, y la estructura essere + $\mathrm{SN}+$ che + proposición, cuando el SN transmite un significado de cuantificación temporal, se abre a varias opciones, pero ninguna con verbo ser: "sono anni che non lo vedo" > "no le veo desde hace años" / "hace años que no le veo" / "llevo dos años sin verle" (Muñiz 1984: 179181; Sánchez Montero 1993: 78-80, 120-121; Musto y Ripa 2008: 421, 423-424). Aunque no ha sido completamente olvidada (Sánchez Montero 1993: 74-78, 127-128; García Dini 1999: 197-200, 203, 206-207; Luque 2008: 62, 64, 66), se ha hecho en general menos hincapié en la falta de correspondencia literal para la construcción 
estativa ir o andar + adjetivo o participio: por norma general en el texto de partida aparecerá essere + adjetivo, un essere que induce a muchos traductores a escribir automáticamente estar, solución a menudo correcta, pero no siempre tan genuina o natural como ir o andar. Es importante, como mínimo, conceder cierto espacio a esta alternativa para contribuir con ella a la variedad y riqueza estilística del texto de llegada:

La lettera è diretta a fra Francesco Luzi [La carta va dirigida] (Sensi 1995: 312)

E quando parliamo di collettività, non intendiamo solo i singoli cittadini, ma anche, e soprattutto, gli Enti locali che, negli ultimi tempi, sembrano essere piuttosto distratti verso questa problematica. [andan más bien despistados en cuanto a esta problemática] (Coppola 2010)

También seguidos de gerundio, ir y andar ofrecen usos en parte distintos y en cualquier caso más numerosos que los de andare + gerundio en italiano, usos que entran parcialmente en el territorio de stare + gerundio o stare + a + infinitivo (compárese la frecuencia de uso de "andan buscándome" y "vanno cercandomi"), y que incluyen asimismo la pasiva inconclusa, inexistente en italiano: "Finora sono stati recuperati dieci cadaveri" > "Van rescatados diez cadáveres" (Sánchez Montero 1993: 76-77, 104117; Luque 2008: 62, 64, 66, 68; Núñez Román 2009: 84-85; Garosi 2010: 129-130). A su vez, para citar otro pseudocopulativo, seguir (o continuar) + adjetivo o participio sólo puede resolverse con restare o rimanere en determinados tiempos ("continué despierto" > "rimasi sveglio"), mientras que en otros se requerirá essere acompañado de adverbio temporal: "sigues enamorado" > "sei sempre innamorato" (Sánchez Montero 1993: 129; Luque 2008: 64, 65).

Tampoco falta algún conector que, al revés de los más arriba enumerados, incluye en italiano un verbo essere al cual se renunciará en la solución castellana, como "tant'è che" o "tanto è vero che", cuya equivalencia más directa, "tanto es así que", suena a veces menos natural que otros intensificadores ("incluso", "hasta el punto de que") o produce precisamente un efecto demasiado intensificador, habida cuenta de la notable desemantización sufrida por la locución en italiano:

il suo maggior pregio era di essere una persona semplice, [...] al posto di gran spessore culturale aveva spessore umano, coltivava gli affetti non convenzionali, 
tanto è vero che è stato molto amato da tanti e altrettanto odiato da alcuni. [como demuestra el hecho de que fuera muy querido por unos y muy odiado por otros / de ahí que fuera querido muy querido por unos y muy odiado por otros] (Gavazza 2008: 209)

Andavamo a cavallo nei boschi, gustavamo le cenette che Concettina ci serviva non nel salone in basso ma sul terrazzino, per lo spettacolo del tramonto. Dio protegge e incoraggia gli audaci, tanto è vero che nessuno in seguito fece la spia né a Gustavo né a mio padre. [Será que Dios protege y alienta a los audaces, porque nunca nadie nos delató ni a Gustavo ni a mi padre.] (Spaziani 2008: 7273)

En resumen: sin pretender establecer porcentajes, y sin entrar tampoco a calibrar el mayor o menor grado de cacofonía a que dan lugar sus repeticiones, es evidente que en la traducción del italiano al castellano tienen lugar con asiduidad supresiones e incorporaciones del verbo ser (en menor medida de estar) y que las incorporaciones corren, por consiguiente, el riesgo de coincidir a breve distancia con otro ser que sí proceda del enunciado original o derive de otros problemas de traducción.

En tal caso, la preceptiva estilística recomienda, como es obvio, la búsqueda de verbos semánticamente más ricos, pero admite también, por lo menos hasta cierto punto, dos maniobras más expeditivas: la elipsis del verbo o su sustitución por verbos pseudocopulativos. Ni el italiano ni el castellano carecen de ambos procedimientos, pero presentan, dentro de cada uno de ellos, diferencias remarcables.

\subsection{Elipsis de estructuras profundas con cópula}

En el primero de los procedimientos mencionados, sin duda, juega con ventaja el italiano, lengua ya en términos generales más dada a la elipsis. Es habitual, pues, al traducir, explicitar estructuras profundas de las que forme parte un verbo, y bien puede tratarse, lógicamente, del verbo ser. Destacan tres estructuras en que lo es a menudo. Una es la formada por rendere + adjetivo $+\mathrm{SN}$, o el mismo esquema con verbo de opinión, valoración, creencia, o de petición o voluntad. Prevalecen, como opciones prioritarias, la traducción literal (“e questo lo rende felice" > "y esto le hace feliz"), la 
fusión de verbo y adjetivo en un verbo derivado del adjetivo ("e questo lo rende orgoglioso" > " y esto le enorgullece") o la transformación del adjetivo en un sustantivo que permita recurrir a un verbo más rico ("y esto le llena de orgullo"); pero el abanico de posibilidades comprende también la dilatación de la frase, es decir, el uso del verbo hacer (o el verbo original en los otros casos) seguido de subordinada sustantiva con verbo copulativo o pseudocopulativo ("y esto hace que esté feliz" / "y esto hace que se sienta feliz"). Normalmente la elección de esta última solución obedece a un escrúpulo del traductor ante el temor de que la sintaxis pueda adolecer de falta de claridad o corrección. No son pocos los que incluso la prefieren pese a dar lugar, con ella, a una repetición de que antes y después del primer verbo, circunstancia que se produce a menudo cuando la frase en cuestión es una relativa (véase nuestra segunda propuesta para el primero de los siguientes ejemplos). Tampoco resulta irrelevante, por otro lado, la extensión y el número de complementos del predicado. En los ejemplos segundo y tercero $\sin$ "affatto" y $\sin$ "su carboni ardenti", o sin "su entrambi lati su carboni ardenti", la sintaxis sintética ("no considera anárquico el poder", "exige pan tostado") tendría mayores visos de verosimilitud:

In caso di aderenza precaria, tipica di fondi particolarmente scivolosi come neve e ghiaccio, si può utilizzare un terzo programma di gestione del cambio automatico, chiamato "ice", che rende ancora più progressive le accelerazioni. [que hace aún más progresivas las aceleraciones / que hace que las aceleraciones sean aún más progresivas / que da aún más progresividad a las aceleraciones] (Gurian y De Prato 1997)

Chi potrebbe dubitare della mia sincerità quando dico che il messaggio di Salò è la denuncia dell'anarchia del potere e dell'inesistenza della storia? Eppure così enunciato tale messaggio è sclerotico, menzognero, pretestuale, ipocrita, cioè logico della stessa logica che non trova affatto anarchico il potere, e che trova esistente la storia, anzi, pone ciò come un dovere. [es decir, es lógico según la misma lógica que no considera en modo alguno que el poder sea anárquico, y que considera que la historia es algo que existe,] (Pasolini 1991 [1975]: 314)

La tradizionale bruschetta richiede il pane tostato su entrambi i lati su carboni ardenti. [exige que el pan haya sido tostado por ambos lados] (Vitta 2013) 
Otra construcción que ocasionalmente hace emerger a la superficie la cópula $-\mathrm{y}$ este último ejemplo se podría adscribir también a este apartado- es el participio pasivo cuando en italiano deja implícitos el verbo auxiliar y el nexo subordinante (pronombre relativo o conjunción). Normalmente la explicitación de la estructura profunda irá acompañada, como ya hemos sugerido más arriba, de una transformación de la voz pasiva en activa, pero no se puede descartar que nos inclinemos por mantener la pasiva:

Lo scarto fra questa lettera e le precedenti, è naturalmente dovuto alla conoscenza diretta dell'opera che lo stesso Leopardi dichiara esplicitamente di avere, confermata tra l'altro dagli "Elenchi di letture" che il poeta annotava diligentemente [al conocimiento directo de la obra que el propio Leopardi declara tener y que es confirmado por las "Listas de lecturas"] (Albertocchi 2000: 184)

Quei sapori delicati [...] ci arrossavano le guance di piacere, e spesso mi lasciavo sfuggire qualche risatina non giustificata da quanto andavamo dicendo. [alguna risita que no estaba justificada] (Venezia 2008: 83)

$\mathrm{Y}$, en tercer lugar, señalaremos los comparativos de igualdad come $+\mathrm{SN}$ o S Prep, que a menudo exigen en español una subordinada introducida por como si y con núcleo verbal normalmente copulativo:

Senza che me ne accorgessi, l'Africa mi faceva innamorare giorno dopo giorno, e io glielo lasciavo fare, accogliendo ogni aspetto di quella terra come un regalo. [como si fuera un regalo] (Rigano 2005: 19)

Otra opción para la misma estructura, siempre con como si, consiste en transformar el verbo copulativo en principal y desplazar el verbo principal italiano a la subordinada. Quedaría reservada para aquellos come que, más que comparar, atenúan la definición del objeto dándole un valor aproximativo, es decir, para aquellos que significan 'una especie de'. Este es como si, o la propia locución 'una especie de' (o una equivalente), son considerados por algunos escritores más correctos o elegantes que un como literal, lo que les lleva a darles prioridad sobre todo en el lenguaje escrito culto:

l'eticità dell'arte deriva dalla sua "bellezza" (anche questo termine è da intendersi in senso lato), e tutto si svolge come in un territorio definito, 
all'interno del proprio linguaggio. [y es como si todo se desarrollara dentro de un territorio definido / y todo se desarrolla dentro de una especie de territorio definido / y todo se desarrolla como dentro de un territorio definido] (Meneguzzo 2005: 11)

\subsection{Elipsis de la cópula}

Si nos concentramos no ya en construcciones que ocultan una parte importante de su sintaxis, sino en la omisión exclusiva del verbo copulativo, el panorama no cambia demasiado: también aquí el italiano demuestra su mayor capacidad de elipsis. La demuestra, ante todo, en la subordinación, donde hace gala de una facultad más amplia de situar tras la conjunción o locución conjuntiva el predicado nominal dejando sobrentendido el verbo essere. Carrera Díaz ya notó en su día esta particularidad a propósito de las condicionales: "se ammalato, non verrà" (Carrera Díaz 1984: 206-207); pero en realidad afecta a múltiples modalidades de subordinada, y aunque determinados predicados concretos omiten la cópula más sistemáticamente, casi como una expresión fija ("non appena possibile", "se possibile", "per quanto possibile", “ove necessario"), no tienen en absoluto la exclusiva sobre dicha omisión:

La gara consisteva in tre giri di nuoto da una riva all'altra. Appena pronti i tre si tuffarono e cominciarono a nuotare. [En cuanto estuvieron listos] (Casciato 2010: 102)

Ma quali sono le imprese artigiane che soffrono maggiormente? Per assurdo sono proprio quelle che nell'immaginario collettivo rappresentano il fiore all'occhiello dell'economia italiana: sartoria e abbigliamento. [Por absurdo que pueda parecer, son precisamente aquellas] (D’Elia 2013)

Insomma: alla fine Ferrante ha perso perché "troppo di sinistra", addirittura "rinchiuso nel recinto della sinistra tradizionale". Invece no, è tutto il contrario: Ferrante ha perso perché "non abbastanza di sinistra", anzi perché "tutta la sinistra è stata troppo terzista". [ha perdido por ser "demasiado de izquierdas", por "haberse quedado encerrado entre las viejas paredes de la izquierda tradicional" ... por no ser "lo bastante de izquierdas"] (Foschini 2006) 
En esta última cita la solución sin cópula del español sería por + adjetivo ("ha perdido por izquierdista"), cuya frecuencia de uso es bastante limitada en registros medios y altos. Todavía lo es más la de donde o cuando $+\mathrm{SN}$, construcción inverosímil en italiano: "donde la última vez", "cuando la guerra" (Santano Moreno 2009: 77-114); o la del que narrativo: "Decimos que qué pesadas, que cuándo dejarán de preocuparse por nuestra vida. Pero lo decimos con la boca chica" > "Diciamo che sono pesanti, e quando la smetteranno di preoccuparsi della nostra vita" (ejemplo tomado de Flores Requejo 2008: 185). Raras son, pues, las ocasiones en que es el español el más sintético, y en general también en el caso en que la omisión se admita en ambas lenguas es probable que un porcentaje elevado de traductores se incline por no ponerla en práctica:

La vettura ha conservato anteriormente l'estetica delle berline torinesi mentre dietro la linea, pur del tutto inedita, ricorda vagamente quella della Flaminia coupé. [aunque totalmente inédita / aun siendo totalmente inédita] (Gurian y De Prato 1997)

Téngase en cuenta, por otra parte, que en español la construcción elíptica presenta, incluso en caso de que el nexo subordinante permita su uso, ulteriores restricciones sintácticas. Como ya hemos observado a propósito de rendere, trovare, richiedere cuando llevan un atributo orientado al objeto directo, se precisa, por lo general, cierta economía en la parte explícita. La estructura por + adjetivo se emplea sobre todo con el adjetivo solo: "Perdió por izquierdista". Basta con que le añadamos un adverbio para que la elipsis tienda a no efectuarse: "Perdió por (ser) demasiado izquierdista". Y con el adverbio negativo ya se hace totalmente inviable: "Perdió por no ser izquierdista". También "aunque" pone más trabas a la elipsis si, por ejemplo, el predicado nominal es un participio con poca proyección adjetival ("migliorato", en la primera de las siguientes citas), si la subordinada depende no del verbo de la proposición principal sino de un verbo subordinado de la misma (de "amarti" y "aver intrecciato" en la segunda cita) o si queda situada entre un sustantivo y un complemento preposicional de éste (cita tercera). Todos ellos factores sin peso alguno en italiano:

La frizione, pur se non leggerissima nell'uso cittadino, non è particolarmente affaticante, mentre il cambio a sei rapporti anche se migliorato, paga in termini di velocità e precisione qualche punto a quello della Monster [El embrague, si 
bien no es muy ligero en la circulación por ciudad, no cansa demasiado, mientras que el cambio de seis velocidades, aunque ha sido mejorado,] (Paolillo 2004)

È stato un privilegio amarti, amico mio, aver intrecciato la mia vita alla tua, anche se per un breve tratto: mi tengo nel cuore un segreto, quello di averti compreso come nessun'altra. E una speranza: che tu conservi un po' di Henriette dentro di te. [Fue un privilegio amarte, amigo mío, entrelazar mi vida con la tuya, aunque fuera por poco tiempo] (Cibrario 2008: 61-62)

Grande impulso ai processi di cambiamento generati dalla riforma viene dato dall'utilizzo, seppure sperimentale, delle tecnologie. [la utilización, siquiera sea a título experimental, de las nuevas tecnologías] (Galeazzo 2004: 116)

Si pasamos a las coordinadas, la no repetición de essere en la segunda proposición quedará a menudo anulada, cuando su atributo sea participial, por la inclinación del castellano a la pasiva refleja, pero incluso en el supuesto de que se optara por conservar la pasiva perifrástica un buen número de escritores repetiría la cópula si se dieran circunstancias tales como que el atributo de la primera proposición perteneciera a una categoría gramatical distinta (fuera por ejemplo un adjetivo) o - de nuevo- como que el participio de la segunda preposición se viera modificado por un adverbio negativo:

Inoltre offrirlo agli studenti gratuitamente significa che è utile e considerato davvero uno strumento molto importante nella formazione dei ragazzi. [que es útil y se considera realmente una herramienta muy importante / que es útil y es visto como una herramienta muy importante] (Falappi 2011)

La scultura è stata dunque pressoché ignorata e mai studiata ma solo inserita nel generale elenco dei Volti Santi considerati dipendenti dal prototipo lucchese. [ha sido, pues, prácticamente ignorada y nunca ha sido objeto de estudio / ha sido, pues, prácticamente ignorada y nunca se ha estudiado] (Maetzke 2002: 1)

No hará falta recordar, por otra parte, que si se suceden por yuxtaposición o coordinación varios predicados que en español requieran uno o unos la cópula ser y otro u otros la cópula estar, la indiferenciación podrá mantenerse en caso de que el verbo 
esté omitido, pero ya resultará menos aceptable o directamente inaceptable si aparece explicitado:

Para mí, lector prematuro y voraz de biografías históricas, esquemáticas y sencillas, Adolfo Suárez se convirtió en Alejandro Magno. Osado, impetuoso, magnánimo, triunfador y siempre rodeado de compañeros fieles y entusiastas. (González de Vega 1996: 12)

tutti sono implicati e partecipi della stessa realtà sociale [todos están implicados y son partícipes de la misma realidad social] (Indovina 2007: 538)

Un tercer ámbito en que la elipsis se practica de forma menos consuetudinaria en español es en el de las frases nominales propiamente dichas, es decir, las proposiciones principales que sobrentienden el verbo copulativo sin que éste haya sido explicitado previamente. Y no nos referimos a las paremias con que a menudo se ejemplifican dichas frases en los manuales de lingüística ("Perro ladrador, poco mordedor"), sino por ejemplo- a titulares de prensa como los que a continuación transcribimos:

Stilista, deejay, 18 auto e tanti gol. La nuova Lazio già pazza di Cissé. [La nueva Lazio ya se rinde a Cissé] (Cardone 2011)

Difesa Gasperini. "Ma quali dubbi[?] Inter da scudetto". [E1 Inter puede ganar la liga] (Sorrentino 2011: 50)

Quizá podría escribirse 'la nueva Lazio loca por Cissé', pero a costa de renunciar al complemento adicional 'ya'. Influye también negativamente el que en un mismo título se sucedan, yuxtapuestas, varias frases nominales, cada una con un sujeto distinto, procedimiento más bien inusual en español: 'Defensa estilo Gasperini: «¿Dudas? Ninguna: Inter ganador»'. La sintaxis nominal, además, es favorecida en italiano por la facilidad con que el verbo essere admite predicados preposicionales (essere + "al telefono", "in partenza", “in ritardo"...), para los que no siempre se encontrará una estructura del mismo tipo en la lengua de llegada.

Ahora bien, los titulares de prensa representan un caso extremo dentro de la vocación elíptica de la lengua italiana. Si salimos de este ámbito y dejamos de lado dificultades sintácticas sobrevenidas, será oportuno, ante todo, puntualizar que la frase nominal tal como se emplea en el estilo periodístico o ensayístico en Italia es perfectamente 
reproducible en español. Otra cuestión es su mayor o menor éxito. Pensemos, por ejemplo, en aquellas ocasiones en que después de punto se empieza con el predicado nominal, normalmente un adjetivo, a veces precedido de adverbio ("más", "menos", "igualmente", "también”...), y a continuación se prescinde del verbo copulativo para colocar de inmediato el sujeto de la frase:

Meno aggressivo il Chievo, che soprattutto nella prima frazione di gara sembra patire il gioco monolitico dei padroni di casa e rimane all'angolo. [Menos agresivo el Chievo] (Carozzi 2013)

O en oraciones conclusivas de este tipo:

L'emendamento - elaborato oltre che da Rodotà, dal capogruppo pidiessino Cesare Salvi e dall'esponente della Rete Diego Novelli - è stato integrato dalle osservazioni del de Vincenzo Binetti e del socialista Silvano Labriola. Accordo larghissimo dunque. Astenuti Msi e Lega Nord e contrario solo il deputato del Psdi Enrico Ferri, ex presidente dell'Associazione nazionale dei magistrati. [Acuerdo muy amplio, pues. Con la abstención de Msi y Lega Nord y la única oposición del diputado] (Bellu 1992)

Nada impide, en castellano, acogerse a la frase sin verbo, e incluso quizá debería reivindicarse como elemento de variación estilística, pero no son pocos quienes la desechan, o la circunscriben al periodismo oral (los telediarios, por ejemplo), lo que indicaría que también en este caso la elipsis termina por efectuarse en menor medida en el lado español. Traductores o correctores insisten a menudo en añadir ese verbo que el enunciado original oculta, llevados o por un exceso de purismo o por la voluntad de ayudar al lector, factor — este último - de gran relevancia en la lingüística contrastiva español-italiano, ya que numerosas diferencias retóricas entre ambas lenguas se explican precisamente por la mayor confianza que el escritor parece otorgar a las habilidades de sus receptores en el país transalpino.

Para terminar, y volviendo a las subordinadas, señalaremos un caso de elipsis mucho más concreto que los hasta aquí reseñados, el que afecta a la perífrasis "non è che”. Pura Guil realizó hace años un estudio de "es que" y "è che" en un corpus de fragmentos televisivos de habla conversacional, estableciendo una presencia mucho mayor del 
primero respecto al segundo (Guil 1994; Flores Requejo 2008: 189-192). En una óptica traductora, cabría completar dicho trabajo subrayando, junto a la correspondencia cero ("es que" españoles que quedarían sin traducir en italiano), la utilidad de dicha locución - como hemos puesto de relieve en 1.1- para varios adverbios y conjunciones fuertemente desemantizados (ya Guil indicaba el "mai" de "come mai", 1994: 117, y Flores determinados usos del "ma", 2008: 191-192), así como para la interrogativa encabezada por che + subjuntivo (la llamada pregunta inductiva):

Un vero evento che neanche i maya avrebbero mai potuto prevedere. Che stia arrivando la fine del mondo? Battute a parte, ieri per la prima volta questo blog "cattivo" ha ricevuto via e-mail un comunicato dell'Amministrazione comunale, inoltrato dall'assessore Emanuela Gervasi, che ringrazio. [¿Acaso se acerca el fin del mundo? / ¿Es que se acerca el fin del mundo?] (Monaco 2011)

Pero lo que aquí nos interesa es que la variante negativa se utiliza, en italiano, tal como también dejó claro el estudio de Guil, mucho más que la positiva, y que puede dejar omitido su verbo, posibilidad que le está absolutamente vetada al castellano:

alla Triumph hanno ripreso a disegnare e costruire moto emozionanti, come la casa britannica aveva saputo fare per anni. Non che la prima generazione di "moto della resurrezione" avessero manchevolezze tecniche. Anzi. Ma, a parte l'enduro Tiger 900, non si può dire che le Triumph della prima generazione trasudassero personalità da ogni poro. [No es que la primera generación] (B.D.P. 1997)

2. Rappresentare, sembrare, parere, constituir, mostrarse, dimostrarsi

\subsection{Consideraciones preliminares}

Entrando en el terreno de los verbos pseudocopulativos, un primer dato que cabe destacar es el protagonismo de que gozan, en italiano, rappresentare y sembrare (o su sinónimo parere). Ambos, desde luego, en castellano pueden ejercer esa misma función, pero la ejercen con más limitaciones, mientras que en italiano pueden sustituir mucho más sistemáticamente a essere tan sólo a fin de evitar un empleo abusivo de este verbo, 
de elevar el registro o de suavizar la radicalidad de la afirmación ontológica. En toda una serie de contextos la traducción con representar y parecer sonará, pues, poco natural, e incluso el significado propio de ambos verbos suscitará alguna que otra sombra de duda. Si X representa o parece Y, no lo es: también en castellano se da ocasionalmente este equívoco, que en la traducción del italiano, si caemos en la hiperliteralidad, se producirá con más frecuencia dada precisamente la mayor frecuencia y desinhibición con que ambos verbos se utilizan como equivalentes de la cópula. Si, por ejemplo, utilizamos representar como pseudocopulativo a propósito de una obra de arte, que es uno de los sujetos que representan por excelencia en el sentido pleno del verbo, crearemos unas expectativas falsas que no se desvanecerán hasta que lleguemos al predicado nominal, y que quizá incluso obliguen al receptor a releer el enunciado. En italiano está tan extendido rappresentare como verbo pseudocopulativo que muy probablemente ni se cause ningún desconcierto momentáneo ni haya nadie que acuse al escritor de incurrir en un defecto de estilo. En cuanto a sembrare / parere, no estará de más, en ciertas ocasiones, adoptar un tono más aseverativo:

Da questo punto di vista il quadro rappresenta una svolta nel suo itinerario artistico. [marca un hito en su itinerario artístico / significa un cambio de rumbo en su itinerario artístico] (Albini 2010: 9)

Filippo Manzoni sembra la vittima designata della Censura. Dopo quella austriaca incapperà in quella paterna, che cercherà, negli anni in cui più difficili erano diventati i loro rapporti, di farne scomparire le tracce dall'epistolario. [Está claro que Filippo Manzoni es la víctima / Todo parece indicar que Filippo es la víctima] (Albertocchi 1996: 195)

\subsection{Traducciones para rappresentare}

A menudo rappresentare transmite un matiz de valoración, o - cuando menos - admite una lectura de este tipo: se dice del sujeto que representa algo positivo o negativo, en general o para alguien en concreto. En tal caso, la traducción literal no plantea inconvenientes, pero no tienen menor validez significar y suponer, empleados en una acepción de la que sí dispone, pero que despliega poco, el significare italiano y que le es 
totalmente ajena a supporre. Otra vía a veces alternativa a ésta, a veces practicable con otro tipo de sustantivos en el atributo, consistirá en traducir el verbo con ser (o equivalente) y agregar un todo $-a$ a dicho atributo. De este modo quizá se exagera levemente el matiz ponderativo, pero se trata, en todo caso, de una infidelidad muy leve: Il 1787, data di pubblicazione del Don Carlos, rappresenta per Schiller una data cruciale [representa para Schiller / significa para Schiller] (Ottomano 2006: 74)

Non solo la gara degli armamenti navali è finita, ciò che rappresenta un grande sollievo per il mondo impoverito dalla guerra, ma si è affermato un nuovo spirito, e si è affermata una nuova coscienza nei rapporti internazionali. [lo que supone un gran alivio] (Meale 1922: 815)

La storia del restauro pittorico rappresenta una testimonianza dell'atteggiamento assunto nei vari secoli verso le opere d'arte [es todo un testimonio] (Artemieva 2001: 13)

Sin el indefinido intensificador, la opción ser también es válida, evidentemente, cuando rappresentare no posea o no queramos darle el sentido ponderativo. Lo mismo cabe decir, sin embargo, de constituir, que es - de hecho - el término más equiparable a rappresentare en cuanto a capacidad de actuar como cópula. Ocurre con él, precisamente, lo contrario que con rappresentare: también en italiano costituire puede desempeñar esa función, pero la desempeña mucho más en castellano, con un radio de acción muy amplio. Lo hubiéramos podido utilizar en las tres citas-ejemplo que acabamos de transcribir, y está habilitado tanto para ponderar como para intervenir con una acepción más neutra y desemantizada:

Sono tutti napoletani (per la precisione Canzio è nato a Salerno e Trapani a Roma, ma entrambi si sono formati all'università di Napoli). E rappresentano il fiore all'occhiello del Mezzogiorno nella governance economica, burocratica, giurisdizionale, bancaria, imprenditoriale. Insomma, Napoli esporta eccellenze. [y constituyen la flor y nata / y configuran la flor y nata] (Abate 2012)

Nei suoi cinque secoli di esistenza la Giuditta [...] si trovò più volte sulla "tavola operatoria" sotto mani artificiose di restauratori. Il trasporto dalla tavola sulla tela, avvenuto negli anni 1805-1807, non rappresenta né l'único, né il più serio 
intervento [no fue la única intervención, ni la más seria / no constituyó la única intervención, ni la más seria] (Artemieva 2001: 13)

Al otro extremo, es decir, entre las opciones que presentan más restricciones, no dejaremos — sin embargo — de consignar equivaler a, conllevar, venir a ser:

Le cultivar a bacca nera nel 2000 rappresentavano il 23\% delle superfici vitate regionali, mentre nel 2009 la quota di superficie occupata da tali vitigni è salita ad oltre il 35,8\%. [representaban el 23\% / equivalían al 23\%] (Bacarella y Nicoletti 2010: 12)

Si potrebbe sostenere che città di bassa densità e città diffusa rappresentano le espressioni usate in due lingue diverse per nominare lo stesso fenomeno, [Podríamos afirmar que ciudad de baja densidad y ciudad difusa vienen a ser las fórmulas utilizadas en dos lenguas distintas para nombrar un mismo fenómeno,] (Indovina 2007: 18)

Hay que advertir, por otra parte, que rappresentare aparece a menudo en voz pasiva, lo que inhibe a algunos traductores poco experimentados de tomar las decisiones oportunas. Dicho en otras palabras: cuesta creer, cuando se ve una construcción aparentemente tan compleja, que uno se halle ante un simple verbo de perfil copulativo. Sí es cierto, en contrapartida, que no faltarán alternativas para proporcionar una solución rica, puesto que esta modalidad, con el predicado nominal convertido en sujeto paciente ('La previsione ... è l'altra differenza' > "L'altra differenza ... è rappresentata dalla previsione"), aumenta el abanico de opciones disponibles: sin dejar de admitir ser o constituir, acostumbra a dar también viabilidad a la serie consistir / residir / radicar / estribar en, así como a transitivos de la órbita de dar, ofrecer, y de formar, integrar, configurar, transitivos susceptibles de ser conjugados bastante libremente en voz pasiva o en voz activa, en este segundo caso con pronombre complemento directo pleonástico:

Nell'ipotesi in cui il componente "Passività" sia stato estinto, trovano rilevazione due elementi del patrimonio netto: il primo elemento è rappresentato dagli interessi, riferibili al componente "Passività", allocati nella voce "Riserve di utili"; il secondo è rappresentato dall'elemento originario. [el primero son los intereses ... el segundo, el componente original.] (Giordano 2010 [2004]: 42-43) 
Il problema più grave per le gerarchie ecclesiastiche era rappresentato dai Valdesi. [lo constituían los valdenses] (Bolognini 2007)

L'altra differenza rispetto al testo del disegno di legge è rappresentata dalla previsione contenuta nel comma 213 del maxiemendamento di un fondo di 50 milioni di euro per il 2007 e il 2008, destinato alla stabilizzazione di ricercatori, tecnologi e tecnici degli enti pubblici di ricerca. [Otra diferencia ... radica en la dotación / consiste en la dotación / viene dada por la dotación / la ofrece la dotación] (FLC CGIL 2006)

Con riguardo alla sola produzione di vini, in Sicilia, nel 2009, è stata di 4.934.271 ettolitri (Tabella 14). Di questa soltanto il 4,3\% è rappresentata dai vini D.O.C. e D.O.C.G., il 34,6\% sono vini IGT e ben il 61\% della produzione è rappresentata da vini da tavola. [sólo el 4,3\% está formado por vinos ... y el 61\% lo integran vinos de mesa.] (Bacarella y Nicoletti 2010: 17)

La serie consistir / radicar / residir / estribar reviste, por lo demás, gran importancia en la traducción de otro tipo de estructura: essere o stare seguido de un locativo con sentido figurado. En general, la elección entre un verbo de dicha serie y estar dependerá o de apreciaciones relativas al registro o del gusto particular del traductor:

il significato ultimo della storia è nella destinazione religiosa dell'uomo, vena sotterranea che solo a tratti sale alla luce del sole ma sempre nutre le radici più profonde onde crescono gli alberi destinati a dar frutti [El significado último de la historia está / radica / reside en el destino religioso del hombre] (Bobbio 1957: 141)

Pero si la localización figurada se hace exclusiva mediante la determinación del sujeto con un tutto $-a$, la opción estar suele perder validez. Habrá que recurrir entonces a uno de los verbos mencionados, al fin y al cabo locativos en su primer significado, o al siempre polifacético ver, si no es que nos inclinamos simplemente por ser, abandonando así el sema de lugar. Según la opción que escojamos, será más o menos conveniente importar el tutto - a mediante una negación restrictiva o eliminarlo:

Perché l'utilità è la proprietà della relazione tra l'essere umano e la cosa (i beni, i servizi sono utili); la felicità, invece, è la proprietà della relazione tra persona e 
persona. Il tradimento dell'individualismo sta tutto qui: nel far credere che per essere felici basti aumentare l'utilità e dunque il consumo di beni. [Y en eso consiste la traición al individualismo: / Y no consiste más que en eso la traición al individualismo:] (Zamagni 2008 [2007]: 45)

Ha sempre creduto in quello che faceva, e forse è tutto qui il segreto del suo e del nostro grande successo. [y quizá no sea otro el secreto / y quizá ahí esté el secreto] (Redazione 2010)

La cosa è molto semplice, e qui sta tutta la profonda umiltà di questo movimento. [Todo ello es bien simple, y es aquí donde vemos la profunda humildad de este movimiento.] (Capograssi 1981: 392)

Nótese, por otra parte, que esta construcción se halla en la estructura profunda de las locuciones tutto qui o tutto lì, muy habituales en italiano oral o coloquial, a las que corresponde, habitualmente, eso es todo o nada más:

- Tutto apposto? Ti vedo un po' giù [...] - Sono solo un po' stanco, tutto qui [Estoy algo cansado. Eso es todo / Estoy algo cansado. Nada más] (Polimeni 2011:34)

\subsection{Traducciones para sembrare / parere}

Si desplazamos nuestra atención a sembrare y parere, aquí se hace todavía más patente el valor atenuativo de modestia con que a menudo es empleado el verbo, una modestia que evidentemente también forma parte de la retórica del castellano, pero en muy menor medida. Si la dosificamos, transformando unos cuantos sembrare o parere en ser / estar (o en otro semicopulativo) delante de adjetivo o sintagma nominal y eliminando alguno más delante de infinitivo o incluso de sustantiva introducida por che, probablemente el conjunto de nuestro texto se beneficiará de ello. Se producen, sobre todo en los malos escritores italianos, concentraciones de estos dos verbos que denotan claras carencias estilísticas. Obsérvese, en el primero de los siguientes ejemplos, la repetición de parere a muy corta distancia, y en el segundo, del mismo autor, cómo la excesiva propensión a insertar un sembrare provoca un error sintáctico ("Non è casuale ... che ..." requeriría, para el verbo subordinado, modo subjuntivo): 
Paiono evidenti due cose, da una parte la modalità di organizzazione dell'urbanizzazione diffusa non pare accettabile, essa presenta, come si è già detto, aspetti negativi sui diversi piani [Dos cosas parecen evidentes: por un lado, la modalidad organizativa de la urbanización difusa no resulta aceptable, pues presenta, como se ha dicho, aspectos negativos en distintos ámbitos] (Indovina 2007: 22)

Non è casuale, cioè, che i processi di auto-organizzazione sembrano indicare quella che è stata definita la tendenza verso la metropolizzazione; il "nuovo" a cui si alludeva in precedenza. [No es casual, pues, que los procesos de autoorganización apunten hacia la que se ha definido como tendencia a la metropolización] (Indovina 2007: 527)

Más arriba hemos aludido a posibles equívocos entre significado pleno $\mathrm{y}$ desemantizado. Serán poco frecuentes, decíamos, pero a ellos debemos añadir los sembrare o parere que, sin dar pie a equívocos, causan un efecto sintáctico extravagante en español, o los que resultan poco eufónicos porque el predicado en cuestión se combina fraseológicamente, por excelencia, con un verbo en concreto. No siempre es fácil, de hecho, diagnosticar ante cuál de los tres fenómenos nos enfrentamos:

La metropolizzazione [...] non dà luogo soltanto ad un nuovo territorio ma piuttosto ad una nuova "metropoli", forse il modello della città futura, che pare ben rappresentato dalla figura dell'arcipelago metropolitano. [que queda bien representado por la imagen del archipiélago metropolitano] (Indovina 2007: 529)

Lo scrittore Casanova normalmente nelle memorie non mente (salvo eccezioni) ma stavolta si è portati a non credergli. Questa storia incestuosa sembra più stupefacente che verosimile. [resulta más sorprendente que verosímil] (De Fusco 2008)

Es importante, sin embargo, aclarar que cabe rehuir la hiperliteralidad sin por ello renunciar al matiz atenuativo. La amplitud de usos de sembrare / parere no sólo abarca formas españolas no atenuadas, sino asimismo una parte del terreno que cubren otros 
procedimientos de atenuación, de tal forma que puede bastar con ajustar o modificar el procedimiento para que la frase ya alcance la fluidez requerida. Uno de dichos procedimientos es el modo condicional. Se tratará o de eliminar sembrare y conjugar en condicional el verbo subordinado, o de sustituir sembrare con decir (u otro verbo de dicción), conjugándolo al condicional. Aunque evidentemente también el italiano se sirve de este modo verbal con idéntica finalidad, en algunos contextos parece sufrir la competencia de sembrare más de lo que la sufre, en español, de parecer:

In questo senso la "rururbanizzazione" [...] sembra condividere molte delle determinanti qualitative dello sprawl nordamericano [...] mentre la differenza sembra riguardare l'intensità relativa dei fenomeni di dispersione all'opera. [En este sentido la "rururbanización" ... compartiría muchos de los elementos ... mientras que la diferencia estaría en la intensidad relativa de los fenómenos de dispersión en curso.] (Gibelli 2007: 281)

All'inizio abbiamo l'impressione che la tattica della ragazza sia improntata solo ad alzare il prezzo; poi si capisce che non è quello il suo obiettivo. Ella sembra volere solo la distruzione del suo corteggiatore. [Se diría que quiere, simplemente, destruir a su galán. / Parece como si solamente quisiera destruir a su galán.] (De Fusco 2008)

Una segunda opción, como ilustra nuestra segunda propuesta para esta última cita, consiste en la construcción ser o parecer + como si (o, en registros más coloquiales, parecer como que). A menudo, en efecto, suena más natural que parecer + que, tanto en frases en que sembrare / parere ejercen función atenuativa como en otras en las que conservan su primer significado, es decir, el valor comparativo:

mi pareva che una voce dolcissima sul terrazzino o a letto, mi stesse leggendo le Mille e una Notte. [era como si una voz muy dulce] (Spaziani 2008: 73)

Si nos interesa mantener una cláusula de infinitivo, la transformación de la sustantiva en comparativa requerirá, evidentemente, sólo el como:

Come è soave e riposante, Giulia mia, [...] rileggere, come la Chiesa fa ogni giorno, il Vangelo! Sembra, a chi passi dalla arida lotta delle cose presenti, dalle divampanti passioni della politica, dalla rovente fiamma delle cose del mondo, 
sembra di entrare nel regno della pace, dell'armonia, del silenzio fecondo. [Es, para quien viene de la árida lucha ... es como entrar en el reino de la paz,] (Capograssi 1979: 194)

Una tercera modificación que respetaría el valor atenuativo de sembrare / parere consistiría en añadir al verbo un complemento indirecto, es decir, en interpretarlo siempre, claro está, que esto sea posible - no como un equivalente de essere ("sembra utile" = "è utile"), sino como si revistiera un sentido de opinión o impresión y se sobrentendiera la persona, el agente de esa opinión o impresión. Fernández Leborans distingue entre un parecer de percepción, sin el pronombre, y un parecer que llama precisamente de opinión, con el dativo (1999: 2443-2446):

Naturalmente non è questa l'occasione per riprendere qui queste riflessioni che sono già state pubblicate negli Atti dell'evento [...] piuttosto sembra utile ricordare i più significativi reperti del corredo funerario della Tomba 14. [más bien resultará útil recordar / más bien nos parece útil recordar / más bien consideramos útil recordar] (Aimi 2010: 111)

Cuarto ajuste posible: debe tenerse en cuenta que el castellano dispone de la perífrasis parece ser que, mientras que en Italia sembra essere che, aunque vivo en el habla popular, está bastante penalizado por la normativa. Si se cumplen las condiciones oportunas (sobre la diferencia entre parece que y parece ser que ha escrito también Fernández Leborans, 1999: 2454), no será una mala estrategia, esporádicamente, incorporar ese ser adicional que incluso en algún caso puede por sí solo hacer ya más eufónica la frase de llegada:

Il celeberrimo Bucefalo, cavallo d'Alessandro Magno, pare che non volesse essere cavalcato da altri se non dal suo padrone; diventando così il simbolo della fedeltà verso un solo padrone. [Parece ser que el celebérrimo Bucéfalo, el caballo de Alejandro Magno, no quería que lo cabalgara nadie que no fuera su amo] (Càrpino 2006)

También nos podemos sentir empujados a escribir la cópula, en este caso cuando la sustantiva se oculta en la estructura profunda ("Parece que son felices" > "Parecen felices"), por razones ligadas a la mayor capacidad elíptica del italiano. Entonces es 
sobre todo estar el que tiende a emerger a la superficie. Pueden propiciar la decisión múltiples factores, desde el sentido de cada atributo en particular hasta su longitud y complejidad, y en muchos casos será el idiolecto el que lleve a tomarla, pero no cabe duda de que, entre "parecen a punto de reventar" y "parecen estar a punto de reventar", entre "parecen condicionados" y "parecen estar condicionados", entre "no parece del todo clara" y "no parece estar del todo clara", un buen número de escritores considerará, en un buen número de contextos, más adecuada o correcta la segunda opción:

Parlarono a lungo, concitatamente, ma questa volta sembravano d'accordo su tutto. [parecían estar de acuerdo en todo] (Izzo Vitiello 2006: 79)

$\mathrm{Y}$ en quinto y último lugar, en ambas lenguas existe la locución adverbial a quanto pare, al parecer / según parece, que complementa a lo que en la modalidad parece que o parece ser que era la subordinada sustantiva y en esta otra pasa a ser proposición principal. Las frecuencias de uso de ambas construcciones en una y otra lengua no se superponen perfectamente, de modo que vale la pena ensayar la opción adverbial para verificar si proporciona una cadena sintagmática más genuina:

Avrebbero voluto che continuassi a suonare ma io volevo notizie fresche di Parigi, cosa va in scena all'Opéra, cosa si dice. Entusiasti di Parigi. Pare che lì ci siano due balli in maschera a settimana, che si viva per andare a teatro e per divertirsi. [Según parece, allí hay dos bailes de disfraces cada semana, / Al parecer, allí hay dos bailes de disfraces cada semana,] (Cibrario 2008: 52)

Hasta aquí nuestras consideraciones se han centrado fundamentalmente en parere / sembrare con subordinada sustantiva. En lo que se refiere a la misma estructura con atributo adjetivo o nombre, y sin que tampoco aquí la propuesta deba considerarse necesariamente preferible a la traducción literal, tan sólo apuntaremos que acostumbran a dar índices de naturalidad muy satisfactorios los verbos de percepción:

Perché i miei capelli sembrano sempre sporchi? [¿Por qué el pelo siempre se me ve sucio?] (Lorenzi 2012)

Aveva una voce fonda senza essere aspra. I suoi comandi erano fermi eppure ti sembravano inviti, non gli potevi negare nulla. [Sus órdenes eran categóricas, y sin embargo sonaban a invitación] (Menaldo 2008: 31) 
La risposta di Verdi fu fredda e risoluta, non sembrava interessato né al soggetto né ad intrattenere ulteriori rapporti con L'Opéra, senza contare che era già in trattative con il teatro La Fenice per Rigoletto. [no se mostraba interesado] (Ottomano 2006: 73)

El verbo ver precedido de pronombre impersonal y pronombre complemento directo se revela un truco precioso para esquivar los conflictos entre ser y estar a que hemos aludido más arriba. Por ejemplo, en la siguiente frase, para eludir un "está ... impenetrable" no muy canónico:

Sta sereno, impenetrabile, compreso della enorme funzione che ha [Se le ve sereno, impenetrable, imbuido de la enorme responsabilidad que tiene] (Capograssi 1981: 393)

Sin el dativo, verse es también más usual que vedersi sobre todo delante de participio pasivo, como ya han observado varios lingüistas (Luque 2008: 64, 66-67; Núñez Román 2009: 86; Garosi 2010: 131-132). Su actuación como auxiliar de dicha voz goza de mayor implantación en castellano incluso en aquellos verbos que la comparten en ambas lenguas ("vedersi costretto", "vedersi obbligato"), además de extenderse a otros muchos principalmente mediante personificación:

È avvenuto in particolare nelle regioni in cui l'immagine della sanità pubblica è stata compromessa dalla pubblicità negativa di alcuni fatti di cronaca. [se ha visto ensombrecida por la publicación negativa] (De Bac 2008)

\subsection{Traducciones para dimostrarsi}

En cuanto a la solución que hemos propuesto para la cita relativa a Verdi, mostrarse, es importante precisar que en italiano mostrarsi y dimostrarsi se utilizan, con función semicopulativa, bastante indistintamente, mientras que en castellano demostrarse sufre un menor grado de desemantización, quedando limitado a una fuerte aspectualidad resultativa ("se demostró un fiasco", "se demostraron inútiles sus esfuerzos"):

Leonilda si dimostrò sorpresa, incuriosita ma per nulla turbata. [Alfonsina se mostró sorprendida] (Spaziani 2008: 75) 
Durante il pranzo mi mostrai amabile e spiritosa come non mai [me mostré más encantadora y graciosa que nunca] (Venezia 2008: 88)

De hecho, incluso cuando prevalece, en italiano, el aspecto resultativo sobre el sentido de apariencia, la traducción literal demostrarse no deja de ocupar un lugar secundario entre las opciones con las que cuenta el traductor, dada la mayor operatividad de revelarse y resultar, que son, pues, junto a mostrarse, las correspondencias más habituales para el dimostrarsi italiano:

La tendenza ancora persistente al panomerismo, a scorgere ovunque elementi dell'epos omerico, si dimostra sempre più insufficiente a dare una spiegazione storicamente valida di dati e fatti linguistici della cultura greca arcaica fuori dell'area ionica. [se revela cada vez más insuficiente a la hora de dar una explicación] (Gentili 2006 [1984]: 98)

Ma la scelta mirava, nello stesso tempo, anche a provvedere l'abbazia di un uomo che fosse capace di rialzarne le sorti, dopo la desolazione in cui da più di venti anni l'avevano precipitata le lotte sveve. E la scelta si dimostrò veramente felice. [Y la elección resultó de lo más acertada. / Y la elección resultó ser de lo más acertada.] (Leccisotti 1960)

No hay que olvidar, además, que resultar puede valer para los dos sentidos a que hemos hecho referencia, dado que presenta una doble acepción, la aspectual ("resultaron heridos" > "rimasero feriti", Núñez Román 2009: 85-86; Garosi 2010: 131) y la que ha sido definida "de constatación" ("Su voz resulta inconfundible”, Morimoto y Pavón Lucero 2007: 50-52, 65-67). Todo ello sin que, por otra parte, tampoco aquí deba rechazarse de antemano la reducción del verbo pseudocopulativo a cópula, solución que se resisten a adoptar muchos traductores por considerarla una simplificación excesiva, pero que no siempre es mejorable con las equivalencias que acabamos de facilitar:

Non ebbi il coraggio di rifiutargli aiuto, anche perché non si era dimostrato cattivo nei miei confronti, soltanto un po' stupido. [entre otras cosas porque no había sido malo conmigo] (MariMalfoy 2012: cap. V)

La politica sanitaria non può certamente ignorare il ruolo di costante evoluzione del cittadino, che si dimostra sempre più informato e con conseguenti capacità di 
giudizio maggiori nei confronti del contesto sociale. [que está cada vez más informado] (Alfano y Bottai 2005: 145)

En el caso de que nos inclinemos — con todo- por la traducción literal, señalaremos, para concluir, dos modificaciones sintácticas de las que es susceptible el dimostrarsi italiano, ambas consistentes en abandonar la forma reflexiva a favor de un demostrar transitivo cuyo complemento directo esté formado o bien por el nombre derivado del adjetivo original y precedido de determinante posesivo o bien por una subordinada sustantiva generalmente encabezada por la cópula en forma de infinitivo. Por lo menos con este verbo en concreto, ambas construcciones se adoptan con más asiduidad en español que en italiano. Normalmente son alternativas opcionales a la sintaxis de partida, pero pueden convertirse en obligatorias o casi obligatorias, sobre todo cuando el atributo es no un adjetivo sino un sintagma nominal:

in questi casi, dove la terapia ufficiale si dimostra spesso impotente, la terapia omeopatica riesce generalmente a conseguire la guarigione completa o almeno un soddisfacente miglioramento della sintomatologia. [la terapia oficial resulta a menudo ineficaz / se revela a menudo ineficaz / se demuestra a menudo ineficaz / demuestra ser a menudo ineficaz / demuestra a menudo su ineficacia] (Granata 2007 [1990]: 96)

L'elemento di spicco dell'esercito cartaginese, durante la seconda guerra punica, fu però rappresentato dalla cavalleria nell'utilizzo della quale Annibale si dimostrò un vero e proprio precursore dei tempi, potendo anche o forse soprattutto contare su un comandante di assoluto valore quale Maarbale. [demostró ser un hombre avanzado a su tiempo] (Rocchi 2011)

Un programma si costruisce col tempo, tessendo anche rapporti, dimostrandosi affidabili, seri. [Un programa lo elaboras a lo largo de años ... demostrando que eres fiable, serio. / mostrándote fiable, serio.] (Bonito Oliva 2005: 101)

Las dos propuestas que ofrecemos para esta última cita distan bastante la una de la otra en el significado primitivo de sus respectivos verbos: quien dice 'mostrarse fiable' debería merecer menor credibilidad que quien dice 'serlo' y, por ende, 'demostrarlo', pero - como se puede apreciar — la diferencia queda muy diluida en virtud de la 
desemantización sobre todo del verbo de apariencia, proceso por el cual se ignora la posibilidad de que uno pueda mostrarse como lo que no es. He aquí otro ejemplo en que ambas opciones son aceptables precisamente porque ni antes ni después ha ocurrido o va a ocurrir nada que desmienta la caballerosidad del personaje:

Il dottor Rodolfo Volandri la aspettava in uno dei tavoli del bar, e fin dalle prime battute si dimostrò un vero galantuomo. [actuó como un auténtico caballero / demostró ser un auténtico caballero] (Russo 2013)

A modo de corolario, y con respecto a la renuncia a la construcción reflexiva ante atributo, subrayaremos que no afecta únicamente a dimostrarsi. De hecho, con otros verbos se deberá llevar a cabo más sistemáticamente:

Un indizio sulla fine del rapporto tra tecnico e società è stato dato più volte dal mister, che a volte si è detto stanco e stressato dal suo stesso mestiere. [ha dicho estar cansado] (Alvino 2013)

\section{Apparire, resultar}

\subsection{Traducciones para apparire}

A diferencia de lo que ocurre en sus intervenciones con sentido pleno, en las que raramente es preciso desviarse de aparecer, cuando apparire toma un cariz de verbo semicopulativo casi nunca admite la traducción literal. Ésta tendrá validez si lo que aparece es físicamente visible, pero incluso en tal caso es probable que el traductor prefiera los verbos de percepción que hemos propuesto en los epígrafes anteriores (2.3, 2.4):

Federer appare di nuovo ben centrato in avvio di partita in un match che esprime fin da subito livelli tecnici elevatissimi. Gli scambi da fondo assomigliano più a un videogioco che a una normale partita di tennis. Lo svizzero appare molto aggressivo e intenzionato a cercare la rete [A Federer se le ve otra vez muy centrado ... se muestra muy agresivo y con ganas de subir a la red] (Pentagallo y De Gaspari 2013) 
Ad ogni modo in entrambi gli autori appare chiarissima la volontà di dare al fascismo un'anima pagana riferita appunto al suo pantheon di Dei [se observa claramente la voluntad] (Marrè 2008: 35)

Aún menos factible, la solución aparecer, en contextos abstractos, a no ser que medie entre el verbo y el atributo un come, o que lo agreguemos:

Inoltre le medie città sempre più appaiono come quelle realtà di organizzazione della vita urbana che ripropone molti dei difetti delle grandi città, senza presentarne i vantaggi [aparecen cada vez más como realidades organizativas / se presentan cada vez más como realidades organizativas] (Indovina 2007: 527)

Se in Sonnambula i protagonisti sono soggetti alle influenze e agli urti dell'ambiente esterno [...], in Norma la sacerdotessa druidica appare responsabile del proprio destino e padrona della propria soggettività [actúa como responsable / aparece como responsable / se presenta como responsable] (Seminara 2006: 193)

Ante estas restricciones que sufre la traducción literal, la costumbre de la lexicografía italiana de definir la acepción semicopulativa de apparire como equivalente a sembrare / parere ha llevado a los autores de diccionarios bilingües a proponer parecer, solución que no condenaremos a priori, pero a la que levantaremos las mismas objeciones que nos suscitaba precisamente como traducción de sembrare / parere. Habrá, pues, contextos en los que funcione perfectamente, sin crear ningún tipo de duda sobre su sentido; otros en que sea aconsejable evitarla por la equivocidad que pueda proyectar su significado propio, y otros en que la sintaxis invite a añadirle o a sustituirla por la cópula, como ocurre a menudo si el atributo presenta forma de participio o de complemento preposicional. Veamos ejemplos de cada una de estas tres variables:

Giacomo [...] annega l'amarezza con una notte d'amore con Lucrezia a cui la figlia quasi si unisce in un finale orgiastico della storia che appare francamente poco credibile. [en una orgía final que no parece muy creíble / en una orgía final que no resulta muy creíble] (De Fusco 2008)

Ma l'ottica implicita nella razionalità privata e in questo tipo di razionalità pubblica è di breve periodo; in un'ottica di razionalità collettiva e di lungo 
periodo, molte scelte possono invece apparire indesiderabili, in quanto responsabili della generazione di esternalità negative e, soprattutto, di processi irreversibili e cumulativi. [en una perspectiva de racionalidad colectiva y a largo plazo, muchas decisiones resultan, al contrario, perjudiciales] (Gibelli 2007: 294)

Al fondo sta la consapevolezza che è impossibile perpetuare modelli insediativi dipendenti dall'automobile in contesti territoriali che appaiono già in condizioni di sovraccarico e congestione; [están ya en una situación / parecen ya estar en una situación / que presentan ya una situación] (Gibelli 2007: 300)

En el caso de que el atributo sea - en cambio - un sintagma nominal, surge a veces la posibilidad de adoptar otra solución que ya hemos sugerido para algunas citas: actuar como, probablemente algo más común que su equivalente agire da / agire come, y por consiguiente - aplicable también, según ilustra la siguiente frase, como recurso para esquivar el verbo ser. Una vez más, entra aquí en juego la indiferenciación entre lo que es y lo que no es, puesto que literalmente decimos no que es, sino que actúa como tal:

La missione di Vienna nel mondo germanico fu di essere il centro propulsore della resistenza europea all'Islam e della difesa dell'unità religiosa con Roma [fue la de ser el centro propulsor / fue la de actuar como centro propulsor] (Perrini 2000)

De entre los verbos de percepción, presentarse, también algo más común —en su uso pseudocopulativo - que presentarsi, es quizá el más cercano a apparire, puesto que comparte con él tanto el sentido de aparencialidad como el aspecto ingresivo, y si gana terreno respecto a su equivalente literal es en parte, efectivamente, porque le roba algo de espacio a aparecer, también en contextos abstractos: "L'aspetto qualitativo appare più complesso" > “se presenta más complejo" (Indovina 2007: 527). Ahora bien, si un pseudocopulativo destaca en nuestras propuestas de traducción no sólo para citas con apparire, sino también con sembrare / parere o dimostrarsi, ése es, sin lugar a dudas, resultar, al que podemos poner al mismo nivel que constituir en cuanto a grado de intercambiabilidad con la cópula, con la ventaja adicional de que la carga semántica que uno y otro conservan les hace operar en contextos casi nunca coincidentes. Vale la pena 
que nos detengamos, pues, a enumerar las múltiples aplicaciones de este verbo en la traducción del italiano al castellano.

\subsection{Versatilidad de resultar}

Empezaremos aclarando que risultare, en su sentido pleno, aunque puede compartir el sentido del español resultar ("ne risultò una grande controversia"), se utiliza sobre todo en su acepción de 'emanar de la lectura de un documento o de la observación de unos hechos', lo que —en la práctica — lo convierte casi siempre en un falso amigo:

A tale riguardo il comma quarto dell'art. 123 prevede che tale informazione venga resa prima della sottoscrizione della proposta e che risulti nei documenti che vengono eventualmente forniti al contraente. [y que figure en los documentos / y que se haga constar en los documentos] (Hazan 2006: 533)

Manzoni, apprezzato come poeta ed intellettuale, lo era assai meno come romanziere, il che risulta, tra l'altro, anche dalla nota recensione del Tommaseo, ove si dice, senza mezzi termini, che 'L'autore degli Inni Sacri e dell'Adelchi si è abbassato a darci un romanzo" [lo era bastante menos como novelista, según se deduce] (Albertocchi 2000: 184)

Seguido de adjetivo, tiene la facultad, sin embargo, de convertirse - como en castellano- en un verbo semicopulativo:

Per ogni strategia, si sono evidenziate le "tattiche" che sono risultate più efficaci e quelle più povere di risultati. [las "tácticas" que resultaron más eficaces] (Gibelli 2007: 297)

No es raro que admita dos interpretaciones, una más cercana a la cópula y otra al sentido pleno, lo que obligará en ocasiones al traductor a enfrentarse al dilema de la sobretraducción o la infratraducción:

Qualora la paziente non risultasse visitata in ambulatorio [...] procedere con la visita preoperatoria [En caso de que la paciente no hubiera sido visitada / En caso de que no hubiera constancia de que la paciente ha sido visitada] (Ospedale Buccheri La Ferla 2002) 
En parte la interferencia de esta acepción de evidencialidad — lo que queda de ella, si queremos decirlo así- (Morimoto y Pavón Lucero 2007: 64), en parte la mayor flexibilidad con que también este verbo acepta como atributo todo tipo de participios hacen que, cuando se comporta como un semicopulativo, risultare no siempre pueda traducirse literalmente. En no pocas ocasiones será aconsejable, en vez de resultar, recurrir directamente a ser o estar, o a otros pseudocopulativos:

la comunità locale non risulta, il più delle volte, tutta autoctona ma è costituita da persone di diversa provenienza (comprese quote più o meno ampie di immigrati stranieri). [la comunidad local no es, en la mayoría de casos, enteramente autóctona] (Indovina 2007: 539)

Il presumibile costo totale dei due istituti, da acquisire anche tramite gli strumenti previsti dall'articolo 145, comma 34, lettera c), della legge 23 dicembre 2000, n. 388, risulta determinato come di seguito: [queda determinado como se detalla a continuación:] (Senato della Repubblica 2012: 36)

Ahora bien, no debe deducirse de estas traducciones no literales que risultare presente un índice de uso globalmente superior al de resultar, porque ocurre precisamente todo lo contrario. El verbo italiano, en realidad, está bastante confinado en el ámbito de los lenguajes administrativo y científico, mientras que se prodiga mucho menos no sólo en textos literarios, sino incluso en ensayos de temática literaria o artística. En español, en cambio, goza de mayor transversalidad. A decir verdad, estamos ante uno de los recursos de la lengua de llegada que más debería esforzarse en emplear el traductor, porque lo habitual es que un texto - un libro, pongamos por caso- escrito directamente en castellano presente muchas más ocurrencias de resultar de las que obtendremos si nos limitamos a utilizarlo para los risultare -o una parte de los risultare - que nos aparezcan en el texto original. Conviene tenerlo presente como potencial sustituto de la cópula, territorio en el que sobresalen determinados usos muy codificados (con adjetivos como "oportuno", "fácil”, “efectivo", “imposible", “necesario", “evidente”, “interesante”, “irónico”), pero en el que en general, y sobre todo en su acepción constatativa, posee gran capacidad de despliegue. No tanto, pues, el resultar cuyo sujeto es directamente afectado por la acción (el de "resultaron heridos"), 
menos desemantizado y — por consiguiente- más limitado en sus posibilidades aplicativas, sino el que indica el efecto, la impresión producidos por el sujeto:

Rispetto alle baraccopoli del sottoproletariato, ma anche rispetto ad alcuni quartieri di edilizia economica e popolare, questi insediamenti che in qualche modo rieccheggiano un'utopia sociale ottocentesca [...] sono abbastanza confortevoli. [resultan bastante confortables.] (Cervellati 2007: 188)

Pero resultar, además de un buen sustituto de ser, también lo es de otros semicopulativos. Así ha quedado sobradamente demostrado en los muchos ejemplos en los que hemos echado mano de él para traducir sembrare, parere, dimostrarsi o apparire, y más abajo comprobaremos su eficacia ante diventare y scoprirsi. Como parecer, admite la adición de la cópula (resulta ser), mientras que en italiano risulta essere, como sembra essere, más bien cosecha mala fama entre los preceptistas; y obsérvese que técnicamente basta con esta adición para que se conviertan en correctos una parte de los resultar literales que habíamos rechazado: 'la comunidad resulta no ser, en la mayoría de casos, enteramente autóctona'. Desde luego, añadir la cópula implica variar ligeramente el registro e introducir cierta connotatividad, efectos secundarios que no permiten efectuar dicha operación en todos los contextos, pero que en algunos contribuyen incluso a mejorar sustancialmente el estilo:

Sono da considerare tali, in un'articolazione molto schematica: [...] - il costo rappresentato dalle esternalità negative che le espansioni suburbane a bassa densità scaricano sui comuni vicini e, in misura superiore, sui cuori metropolitani (che nel rapporto "inquinatore/vittima" risultano i meno inquinanti, ma i più inquinati) [que en la relación "contaminador/víctima" resultan ser los menos contaminantes, pero los más contaminados] (Gibelli 2007: 293-294)

Algo más hace bajar el registro resulta que, inédito en italiano con la función de marcador del discurso que a menudo adquiere en español hablado. Determinados usos de poi irían en la misma dirección (Flores Requejo 2008: 201-202), pero también algunas perífrasis verbales presentan, en ocasiones, una carga expresiva similar: 
E io: "comunque la tua parola vale la mia: i documenti dicono che veramente io mi sono fatta male e sono finita in ospedale. Se poi tu non mi credi, vuol dire che qualche cosa che c'era tra noi ora non c'è più'. [Si resulta que no me crees,] (Amadei 2007: 48)

La Vallière balza in piedi, come se l'avesse punto una vespa. Viene fuori che la sua vespa è - come dice lui stesso - un'idea brillantissima. [Y ha resultado que la avispa en cuestión era — como ha dicho él mismo- una idea genial.] (Cibrario 2008: 54)

- Perché proprio piazza dei Martiri? - Dopo una mostra mi capitò di essere invitato a una cena: di fronte a me era seduto il proprietario dello spazio di piazza dei Martiri. Un mese dopo avevo concluso. [-Resulta que me invitaron a cenar, después de una exposición, y delante de mí tenía sentado al propietario del local de Piazza dei Martiri.] (Bonito Oliva 2005: 115)

Recordaremos, finalmente, que resultar es una de las soluciones habituales para la construcción riuscire + adjetivo ("mi riesce difficile" > "me resulta difícil"), carente de equivalencia literal propiamente dicha.

\section{Diventare, quedar(se)}

\subsection{Traducciones para diventare}

De todos los verbos semicopulativos, diventare y divenire - sinónimos no perfectos pero casi- son los que más han atraído la atención de los expertos en lingüística contrastiva español-italiano, sin duda a causa de la altísima frecuencia de uso sobre todo del primero, frecuencia de uso que hace a todas luces insuficiente la equivalencia convertirse en, que es la que suele facilitarse como traducción más directa. Dichos expertos han trazado una lista bastante completa de propuestas, sobre la que no será necesario que insistamos aquí: transformarse en, ponerse, hacerse, quedarse, volverse, 
llegar a ser, más las variantes cultas o arcaizantes tornarse, mudar, devenir (Bermejo Calleja 1994; Carrera Díaz 2007: 6; Prestigiacomo 2008). La lista en cuestión, además, ha sido siempre objeto de interés por parte sea de quienes se ocupan de la contrastiva con otras lenguas dotadas de verbos similares a diventare (devenir, become, werden), sea por parte de los profesores de español como lengua extranjera (Martínez Labiano 2008; Martínez Vázquez 2011; Correia Palacios 2012), e incluso los lingüistas puros han mostrado especial predilección, dentro de la temática verbal, por los pseudocopulativos aspectuales, también llamados verbos de cambio (Porroche Ballesteros 1988: 127-142; Porroche Ballesteros 1990: 55-120; Marín Gálvez 2000: 155-219; Pino 2001; Morimoto y Pavón Lucero 2007: 25-52, por citar sólo algunos clásicos). Precisamente a la luz de los estudios no estrictamente vinculados a la filología italiana, nos permitiremos agregar a la lista cuatro opciones, concretamente pasar a ser, acabar o terminar siendo (o por ser), resultar y revelarse (proporcionaremos ejemplos de estos dos últimos más abajo):

- Erano tutti collezionisti di Lucio? - Molti, dal momento che Lucio aveva aperto la sua galleria alla fine degli anni Sessanta ed io soltanto nel 1986. Ma i più giovani divennero subito i miei primi clienti di Napoli (è il caso di Ernesto Esposito e Fortuna e Bruno Condi) proprio perché avevano la necessità di un interlocutore con una linea diversa da quella di Lucio. [Pero los más jóvenes pasaron a ser en seguida mis primeros clientes napolitanos / Pero los más jóvenes se hicieron en seguida clientes míos, los primeros que tuve en Nápoles] (Bonito Oliva 2005: 97)

L'ideale morale, naturalmente, non può esimersi da una presa di coscienza politica, e questo diventa uno dei nodi centrali dell'intera produzione drammatica schilleriana. [una toma de conciencia política, que acaba siendo una de las cuestiones clave de toda la producción teatral schilleriana] (Ottomano 2006: 74)

Cuando el atributo de diventare o divenire es un adjetivo, vale la pena explorar la posibilidad o bien de sintetizar ambos términos en un solo verbo, derivado del adjetivo o de un sinónimo del mismo, o bien de escoger, siempre dentro de la familia de palabras del adjetivo, el sustantivo y buscarle un verbo: 
Anche il legame tra la pubblicità digitale e social media sembra sia diventato sempre più forte. Un annuncio web su 8 è ormai "socialmente attivo", nel senso che direziona i consumatori sui social network richiedendo un "like" su Facebook o di "seguire” su Twitter. [También el vínculo ... parece haberse ido fortaleciendo.] (Redazione 2013)

Siccome poi si suppone che le cose appartenenti alle diverse specie siano misurabili, è diventato comune l'uso di identificarle sic et simpliciter con le particolari quantità che delle specie corrispondenti esse rappresentano. [se ha generalizado la costumbre de identificarlas] (Scapparone 1998: 219)

Internet diventa utile anche contro l'insonnia [también revela su utilidad / también resulta útil / también se revela útil] (Redazione 2009)

Se ha insistido poco, por otra parte (Carrera Díaz pone el ejemplo "Tu da grande cosa vuoi diventare?” > “Tú, de mayor, ¿qué quieres ser?”, 2007: 6), en la opción de traducir simplemente diventare por ser. La diferencia aspectual, es decir, el matiz de cambio o resultado, podrá acaso facilitarse mediante la adición de un adverbio, o conjugando el verbo en un tiempo distinto al original:

Giacomo lo vedevo ancora, ma tutto era diventato più difficile. [...] La mia conversa era tornata, e uscire di notte mi era diventato impossibile. [Seguía viendo a Giacomo, pero ahora todo era más difícil. ... y salir de noche ya me resultaba imposible.] (Menaldo 2008: 33)

Non è più ricco e si adatta - arrivando ad Ancona - a vivere a pigione nella casa di un usuraio ebreo. [...] Nella modesta sistemazione il destino riserva però una sorpresa: una ragazza giovane, golosa e disinibita che diventa la compagna di pranzi e conversazioni. [una muchacha joven, golosa y desinhibida que será su compañera de comidas y pláticas] (De Fusco 2008)

No es, en todo caso, recomendable obsesionarse demasiado con transmitir dicha diferencia. Puede que ya la deje clara el contexto (a menudo diventare es redundante), o que por introducirla forcemos la formulación y acabemos así perjudicando la fluidez y naturalidad del conjunto oracional: 
Gli uomini di quell'età diventano, ho avuto modo di notare, vulnerabili come fanciulle e suscettibili come matrone. [Los hombres de esa edad son tan vulnerables / Los hombres a esa edad se vuelven tan vulnerables] (Venezia 2008: 84)

L'iniziativa, originariamente, doveva essere un workshop sul progetto, ma la scoperta della Tomba 14 finì per diventare, per certi versi, il momento di maggiore interesse. [acabó siendo de hecho, la noticia que suscitó mayor interés] (Aimi 2010: 111)

\subsection{Versatilidad de quedar / quedarse}

Pero, volviendo a los pseudocopulativos, hay que señalar, como en epígrafes anteriores, que también entre las equivalencias de diventare sobresale un verbo por encima de todos los demás, y esta vez se trata de quedar, quedarse. Con esto no queremos decir que sea la solución más habitual para diventare, porque, para empezar, incluso dejando de lado matices semánticos, quedar(se) no suele admitir como atributo un sintagma nominal y diventare sí. Pese a ello, es ampliamente reconocido como el semicopulativo más utilizado en español (Porroche Ballesteros 1990: 104; Pino 2001: 251, 257, 260) y, por consiguiente, demuestra gran versatilidad en la traducción de múltiples verbos italianos pertenecientes a la categoría gramatical que nos ocupa, sobre todo precisamente - en la traducción de los de contenido más aspectual. En primer lugar, desde luego, es el equivalente más común de rimanere y restare. Pocos usos de ambos verbos, también muy utilizados en italiano, rehúyen, en efecto, esta correspondencia. Uno de esos pocos desencuentros se produce porque, como diventare, rimanere y restare aceptan en el predicado un sintagma nominal:

A tutt'oggi l'eliminazione dell'acqua dalle murature rimane un problema aperto a cui si cerca di dare risposte con sempre nuovi prodotti [sigue siendo un problema] (Gasparoli y Talamo 2009 [2002]: 93) 
Si quedar(se) indica la consecución de un estado para permanecer en él, seguir subraya la continuidad en un estado que ya se daba con anterioridad. La corta distancia que separa uno y otro sentido hace que ambos puedan quedar cubiertos por rimanere / restare. En español, en cambio, no siempre se confunden, tampoco cuando el verbo lleva predicado no nominal. En la siguiente frase, por ejemplo, seguir resulta como mínimo más correcto que quedar:

Altre volte le privatizzazioni in senso sostanziale hanno riguardato solo partecipazioni di minoranza per provocare afflusso di capitale di rischio privato nella società, che però resta sotto il controllo dell'ente pubblico. [sigue bajo el control] (Cameriero 2008: 7)

Una problemática similar suscita otro competidor que entra en juego en este mismo campo semántico: permanecer, mucho más común que permanere. Así, "rimanere zitto" puede significar tanto "quedarse callado" como "permanecer callado". En castellano quizá también la diferencia sea obviable, porque uno puede — por ejemplo_ "quedarse callado un buen rato", y entonces la elección dependerá únicamente de condicionantes estilísticos, pero habrá quien considere que los acontecimientos previos hagan preferible inclinarse por una de las dos opciones, es decir, que sólo te puedas quedar callado si antes has estado hablando. Circunstancia que no se da, o no se hace constar, en un pasaje como el siguiente:

Salirono in carrozza, prima classe. [...] Venti minuti di viaggio. Una decina di chilometri di campi coltivati e cascine, campagne tagliate dal Lambro e dal tracciato di qualche stradina. Le ruote del vagone sferragliavano sulle rotaie e la locomotiva correva portando con sé i vagoni, Lisander e Anna Lucia. I due rimasero zitti per l'intero tragitto, [...] Erano tristi nel profondo. [Ambos permanecieron callados durante todo el trayecto] (Mari 2011: 542-543)

Equivalencias menos importantes de rimanere / restare son, en cambio, mantenerse, restar y pasar, estas dos últimas bastante circunscritas a determinadas fórmulas negativas: 
Al numero telefonico di Ge.Ri. [...] risponde un disco perennemente incantato su "rimanete in attesa, prego, per non perdere la priorità acquisita", ma di risposte non se ne hanno. ["manténgase a la espera] (Marmugi 2011)

Non gli restava che ripartirsene [No tenía más remedio que marcharse / No le quedaba otro remedio que marcharse / No le restaba sino marcharse] (Spaziani 2008: 76)

Comunque, quello strepito non poteva rimanere inascoltato: dopo qualche istante le zie, la mamma, la servitù, tutta una piccola folla in subbuglio si riversò nella stanza [De todas formas, aquel alboroto no podía pasar inadvertido] (Capriolo 2008: 43-44)

Dicho esto, y retomando la raíz de nuestras reflexiones, la fuerza expansiva de quedar(se) supera con creces el terreno que pueda ceder ante rimanere / restare. Básicamente, y limitándonos al ámbito pseudocopulativo, encuentra campo abonado en los no poco frecuentes usos de stare y essere en los que ambos verbos sugieren - $\mathrm{O}$ cabe interpretar que sugieran - un matiz durativo o prolongativo, dicho de otro modo, en los que precisamente podrían ser sustituidos por rimanere o restare. Stare, de hecho, se distingue de essere, en italiano, en buena medida por su acercamiento a estos otros dos verbos, como demuestran los muchos contextos en los que es indiferente decir "stare zitto" o "rimanere zitto":

- Mi dispiace, non posso farti stare qua, ci sono delle persone che mi hanno chiesto di fare la guardia alla casa... [Lo siento, no puedo dejar que te quedes aquí] (Paravidino 2001: 5)

Un lento, difficile duello che combattevo con ogni mezzo possibile, come quando per provocarti mi feci sorprendere nuda nella vasca da bagno, ma non ti permisi di toccarmi, e tu stavi lì a guardarmi sconvolto, inebetito... ah, che trionfo vederti ridotto così... [y tú te quedaste allí mirándome turbado, embobado... / y tú permanecías allí mirándome turbado, embobado...] (Capriolo 2008: 41)

En cuanto a essere, la oportunidad de traducirlo con quedar(se) surge principalmente cuando le sigue un participio, y más concretamente cuando forma una perífrasis pasiva 
impersonal y el verbo en cuestión admite ser interpretado en clave resultativa (Sánchez Montero 1993: 73; Luque 2008: 67). La traducción más estricta de estas oraciones sería o una pasiva propiamente dicha o, más habitualmente, una pasiva refleja: "se sitúe", "han sido contextualizadas" o "se han contextualizado", "se circunscribe", en los ejemplos que transcribimos a continuación. Con quedar + participio cometeremos, pues, si así se quiere, una pequeña imprecisión: el verbo italiano muestra la acción en su desarrollo, nosotros la mostraremos como un punto de llegada con valor permanente. Ahora bien, siempre que este segundo sentido responda a la realidad, la licencia metonímica podrá considerarse justificada en honor a la mayor frecuencia de uso de quedar + participio en castellano:

Con il martinello così posizionato ruotare la manovella fino a che la sua base, quando viene ad appoggiarsi a terra, sia posta entro la fascia di rotolamento delle due ruote. [quede situada dentro de la banda de rodadura] (Fiat Auto 1985: 61)

Prima di rispondere, prendendo ad esempio il linguaggio dell'arte, bisogna vedere se esiste ancora un'arte italiana, il che ci riporta alle domande iniziali, che però ora sono state contestualizzate sia in senso storico che linguistico [han quedado contextualizadas] (Meneguzzo 2005: 11)

"introdurre regole di buona progettazione locale": anche se il tema è stato centrale nel dibattito culturale e nelle proposte riconducibili al New Urbanism, non è considerato particolarmente efficace per contrastare gli effetti negativi dello sprawl, poiché circoscritto alla microscala territoriale [ya que queda circunscrito a la microescala territorial] (Gibelli 2007: 298)

Algunos de estos participios pueden leerse simultáneamente como parte de una perífrasis pasiva y como adjetivos, entendiéndose —en este segundo supuesto- que ya el italiano está describiendo un estado, es decir, que su verbo essere equivale non tanto a ser como a estar: 'ya que está circunscrito a la microescala territorial'. Bajo este prisma, la infidelidad sería de otra índole, más bien la de un exceso de acción, puesto que es empleado un verbo resultativo para uno originalmente estativo. En cualquier caso, la desviación se mantendría dentro de unos límites igualmente aceptables. Simplemente puede que resulte necesario, para salvar dicha diferencia, modificar la conjugación a favor de un tiempo perfectivo: 
La cosa mi colpì doppiamente. Dunque Concettina, ora già madre, aveva voluto la sua prima notte, e tranquillamente poteva parlare di altro senza aver l'aria di essere marchiata da un ricordo terribile. [sin que pareciera haber quedado marcada / sin que pareciera estar marcada] (Spaziani 2008: 67)

De hecho, aunque no es un uso muy conocido por los hablantes de italiano no nativos, essere con atributo participial o adjetival posee la facultad de presentar ya de por sí un valor más resultativo que estativo. La ejerce muy ocasionalmente, esta facultad, pero cuando lo hace no es que admita la traducción quedar, sino que prácticamente la exige:

Leonilda non ritornò nemmeno sull'argomento, e gli zii trovarono modo di far sapere alla regina che la fanciulla era già fidanzata. Io fui mezza contenta e mezza scontenta, e negli anni seguenti il mio pensiero ritornò continuamente a quell'ultimo incontro senza speranza per nessuno. [Yo me quedé entre satisfecha e insatisfecha,] (Spaziani 2008: 76-77)

Añadamos aún, a todo lo dicho, el quedar que indica la impresión producida por algo cuando es colocado en un determinado lugar, por excelencia una prenda de ropa cuando alguien se la pone: "Quel vestito ti sta piccolo" > "te queda pequeño", "così è troppo piccolo" > "así queda demasiado pequeño". O el que marca una distancia espacial o temporal:

Sono lontani i tempi [...] in cui Giacomo sbarcava a Parigi o Londra e affittava interi palazzi! [Quedan lejos los días] (De Fusco 2008)

Y, más allá de su incidencia en la traducción de essere y stare, señalemos que, conforme a su extraordinaria aptitud para ejercer de auxiliar de pasiva, quedar(se) seguido del participio correspondiente - incluso se presta a invertir, siquiera sea excepcionalmente, la tendencia habitual de la traducción italiano-español a transformar voz pasiva en voz activa:

Dietro quel muro mi innamorai ancora di più. E dietro quel muro il mio amante Bernis s'invaghì di Caterina. [mi amante, Bernis, quedó prendado por Caterina.] (Menaldo 2008: 33)

Jane può alla fine sposare Colden, avendolo convertito nel frattempo al matrimonio e alla religione. Così la vampa delle passioni si riduce a un mite 
fuoco acceso nel caminetto di casa. Depurato di ogni ambiguità, il romanzo « sentimentale " è ormai simile a una conchiglia vuota. [la llamarada de las pasiones queda reducida a un sosegado fuego] (Bulgheroni 1965: 238n)

Se repite, con esta operación, el sutil movimiento que hemos observado al utilizar el propio quedar(se) para traducir las pasivas con essere, es decir, el desplazamiento del desarrollo de la acción a su resultado.

\section{Revelarse, scoprirsi}

Un último apartado merecen dos pseudocopulativos, revelarse / rivelarsi y scoprirsi, muy próximos entre sí en su primer sentido de 'destaparse', 'dejar de ocultarse'. Revelarse es ligeramente más frecuente en español que rivelarsi en italiano. Lo hemos incluido entre las opciones válidas para dimostrarsi y diventare, pero no se agotan aquí sus posibilidades. No hará falta recordar su combinación casi fraseológica con adjetivos como "eficaz", "insuficiente”, "satisfactorio", "útil”, "inútil”, que hacen de él un buen candidato a sustituir a la cópula cuando es ésta la que introduce dichos términos ("in un modo che sia efficace" > "de un modo que se revele eficaz", Indovina 2007: 22). Veamos también cómo, en ocasiones, da una buena réplica precisamente a scoprirsi:

Mi diedi con tutta me stessa al vicino di casa, scoprendomi fra le sue braccia esperta di ogni cosa, anche se era la prima volta. [revelándome entre sus brazos] (Venezia 2008: 85)

En realidad, ya en su uso transitivo scoprire abarca un radio de acción superior al de descubrir, requiriendo para una parte de sus usos las traducciones destapar ("una pentola"), enseñar o mostrar (“i denti”, "le proprie intenzioni”) y revelar, estas dos últimas aún más importantes si lo que se traduce es italiano antiguo, dada la importancia que tenía en este verbo, junto a la acepción de adquirir el conocimiento de algo, la de comunicarlo a otras personas: 
pregoti (se fra l'arme han loco i preghi)

che 'l tuo nome e 'l tuo stato a me tu scopra, [que tu nombre y condición me reveles,]

acciò ch'io sappia, o vinto o vincitore,

chi la mia morte o la vittoria onore.

(Gerusalemme Liberata, XII, 60)

Pero no es menor la ductilidad de que da prueba scoprirsi como pseudocopulativo, lo que, sumado a la inexistencia de un equivalente literal en español (lo más cercano sería descubrir + ser o estar), exige una nutrida baraja de equivalencias. La particularidad de este verbo consiste en que conserva, en mayor o menor medida, su sentido epistémico: el sujeto descubre en sí mismo una cualidad. Hay que calibrar, pues, en función del contexto, en qué medida mantiene dicho sentido $\mathrm{y}$, en consecuencia, si es preferible reproducirlo o desecharlo, porque ambos caminos conducen a soluciones diferentes. A menudo reproduciéndolo sobretraduciremos, desechándolo infratraduciremos, y no escasearán las ocasiones en las que ambas lecturas serán defendibles y las diferencias entre ellas intrascendentes. La decisión, en cualquier caso, deberá tomarse:

Poi, alla tenera età di nove anni, si è aggiunta la passione per lo sport di famiglia, ovvero il tennis, per il quale mi scoprii molto dotata. [descubrí estar muy dotada / vi que estaba muy dotada / resulté estar muy dotada] (Garassino 2011)

E a Bologna ha promosso comici che, usando il repertorio comico teatrale locale, hanno dialogato con la comicità televisiva, attirando sia un pubblico giovane, sia uno attempato, che si è scoperto attratto da una comicità teatrale dai tempi più serrati e dalle maschere diversamente caratterizzate. [que ha descubierto su atracción por una comicidad teatral / que se ha sentido atraído por una comicidad teatral] (Guagnano 2008) 
La primera lectura, en rigor, equivaldría a no considerar el verbo pseudocopulativo. De hecho, ni siquiera hay unanimidad entre los expertos sobre la condición pseudocopulativa de sentirse, que algunos excluyen de la lista por no estar lo suficientemente desemantizado (Morimoto y Pavón Lucero 2007: 54, 63-64). En lo que aquí nos atañe, si nos ceñimos a las soluciones con pseudocopulativo pero damos a la categoría - como hemos hecho a lo largo del artículo - su interpretación más elástica, la traducción de scoprirsi quedaría abierta tanto a verbos de percepción que conservan - aunque modificado - el sentido epistémico (sentirse, encontrarse, verse), como a otros que tienden a sacrificarlo a favor de la mera aspectualidad (resultar ser, acabar por), aunque no puede afirmarse que ni unos ni otros carezcan totalmente del otro sentido:
All'improvviso, poi, Vito sparì e io mi scoprii irrimediabilmente sola nella vastità del desiderio. [me encontré / me vi] (Ciriachi 2009)
Non dovevo lasciarmi prendere dalla malinconia, non potevo permettermelo. E mentre spazzolavo con vigore la vasca da bagno, mi scoprii in lacrime. Lacrime di paura, e di consapevolezza. [me vi hecha un mar de lágrimas / terminé hecha un mar de lágrimas / terminé llorando a lágrima viva] (Rigano 2005: 156)

Aunque quizá para scoprirsi pueda parecer más empobrecedora que para otros verbos, también aquí tiene cabida, evidentemente, la traducción mediante la cópula, con la eventual adición — tal como hemos sugerido para diventare- de complemento adverbial. Los distintos tipos de complemento entre los que nos será dado elegir pondrán igualmente de manifiesto la duplicidad semántica de este verbo italiano, ya que nos inclinaremos por uno de tiempo si queremos proporcionar aspectualidad, pero en otras ocasiones nos orientaremos hacia otros semas:

niente, non rimanevo incinta. La mia ginecologa, (sempre lei!!) mi consigliò una psicologa, [...] e, miracolosamente, dopo solo tre sedute, mi scoprii incinta. [ya estaba embarazada] (Cristiana 2007)

Pensavo di poter condurre a termine la revisione in una quindicina di giorni al massimo, ma mi scoprii inadatto a un tal genere di lavoro. Sentii infatti il 
bisogno [...] di rifare l'indagine ex novo, applicandomi ad essa per circa un anno. [pero resulté no ser apto para ese tipo de trabajo. / pero en realidad no era apto para este tipo de trabajo] (Leone 1984: 9)

\section{Conclusiones}

Como ocurre con cualquier batería de términos gramatical o semánticamente muy afines, en la traducción de los verbos copulativos y pseudocopulativos es importante establecer cruces múltiples y variados entre ambas series, la de la lengua de partida y la de la lengua de llegada, sin quedar, pues, aprisionados en las correspondencias lineales - las literales - y sin dejar de tener muy presente todo el paradigma de opciones. A uno y otro lado encontramos básicamente los mismos verbos, pero su frecuencia de uso y su capacidad de desemantización varían sensiblemente. Simplificando un poco, diremos que son superiores, en italiano, respecto a las que ostentan sus más directos equivalentes españoles, las de rappresentare, sembrare / parere, dimostrarsi, apparire, diventare y scoprirsi; en español, respecto a las de sus equivalentes italianos, las de constituir, consistir, resultar, mostrarse, verse, revelarse, presentarse y quedar(se).

El fenómeno se da en cada caso según variables específicas y debe entenderse siempre en términos relativos, es decir, dentro de una estricta relación comparativa con los usos del mismo término — etimológicamente hablando - o del término más cercano en la otra lengua: es evidente que de lo dicho no debe deducirse, por ejemplo, que parecer o rimanere / restare no gocen de un alto protagonismo en el ejercicio de la función semicopulativa. En lo que se refiere a las líneas de tendencia que se recaban de las disimetrías detectadas, parece observarse — sobre todo si tenemos en cuenta la fuerte implantación de quedar(se) y resultar - un gusto ligeramente mayor del español por los pseudocopulativos aspectuales, mientras que en italiano tendrían algo más de peso los verbos aparenciales, en los que se dice la manifestación exterior en vez de la esencia, lo cual a su vez sería indicio de un peso mayor de la preocupación atenuadora o de modestia. Queda confirmada por el análisis comparativo, en cualquier caso, la 
importancia que revisten en las dos lenguas ambos tipos de desplazamiento semántico, así como la dificultad — sobre todo en algunos de los verbos— por deslindarlos.

No menos interesante es, sin embargo, que hayamos juzgado oportuno contemplar verbos que sólo muy raramente (Demonte y Masullo 1999: 2519) son incluidos por los lingüistas en las listas de pseudocopulativos, probablemente porque no admiten como atributo un adjetivo: representar, significar, constituir, consistir en, radicar en. El estudio contrastivo aquí desarrollado contribuiría, pues, a reconocerlos como tales, pero — dicho esto- habría que plantearse cómo catalogarlos. En general, se ha tendido a agrupar los pseudocopulativos no aspectuales o bajo la etiqueta 'aparencial' tomada lato sensu, o bajo la de 'pseudocopulativos modales', por cuanto todos ellos presentan el atributo según el modo en que es percibido por el hablante, un hablante que no se compromete sobre el valor de verdad de su enunciado (Porroche Ballesteros 1990: 121144; Morimoto y Pavón Lucero 2006; Morimoto y Pavón Lucero 2007: 53-67). Los verbos representar y significar (quizás también constituir) podrían entrar en esta última categorización si vemos en su uso semicopulativo una extensión de su acepción ponderativa: 'él representa / significa mucho para mí' > 'la superpoblación representa / significa / constituye un problema' (para alguien o para todo el mundo y, por consiguiente, también para el hablante). Pero no parece que - centrándonos en el primero de dichos verbos - todos los representar y aún menos todos los rappresentare semicopulativos sean reconducibles a dicha lectura, o por lo menos resultan igual de plausibles otras, como la de tomar en consideración el primer sentido del término, que más bien nos situaría en un ámbito de aparencialidad propiamente dicha, sin que deba por fuerza hacerse depender de un sujeto experimentante: si X representa Y (si el cuadro representa el bosque) no es $\mathrm{Y}$ (no es el bosque), decíamos, del mismo modo que si $\mathrm{X}$ parece $\mathrm{Y}$ tampoco lo es, y en ambos casos esta negación es justamente lo que se anula, dándose por válida la identificación entre — por decirlo platónicamente - la copia y el modelo, la apariencia y la esencia.

Pero existe aún una tercera interpretación posible: "Il territorio consortile è rappresentato da 5 province piemontesi e 5 lombarde" (Consorzio Tutela Gorgonzola 2005). Esta frase se relaciona con los usos de constituir en que este verbo no indica la importancia de algo para alguien, sino la formación de una unidad con una pluralidad de 
elementos, siendo grosso modo intercambiable con formar, integrar, configurar (Climent Roca 2000: cap. 4.1.3). En el caso de representar, se trataría de la acepción por la que no sólo $\mathrm{X}$ simboliza $\mathrm{Y}$, sino que, además, $\mathrm{Y}$ es un genérico respecto a $\mathrm{X}$ : "Góngora representa al escritor barroco" (Diccionario Salamanca). Se perfila, en definitiva, dentro de este cuadro ampliado de los verbos pseudocopulativos, y en intersección con los dos modelos que se han teorizado tradicionalmente, un tercer tipo de desplazamiento por contigüidad que respondería a la forma más proverbial de metonimia, la que afecta a la parte y al todo. "El regalo consiste en una serie de cajitas", es el primer ejemplo del Diccionario Salamanca para la voz consistir. Y con radicar, estribar, residir, no hacemos sino escoger y aislar uno de los múltiples aspectos, elementos o factores potencialmente susceptibles de aparecer en el predicado: si hablando de una negociación decimos que "La dificultad estriba en convencer al vicepresidente" (en formulación copulativa "Lo difícil es convencer al presidente") focalizamos la atención en uno de los componentes de la negociación o en una de entre todas las dificultades reales o posibles de la misma. Todos y todas las demás son ignorados, y ahí está, de hecho, la clave de la desemantización. Si podemos utilizar formar, integrar, configurar, normalmente ésta se da en menor medida, lo que prevé por excelencia - pluralidad en el sujeto y unidad en el atributo: 'El territorio del consorcio son cinco provincias / está formado por cinco provincias / está constituido por cinco provincias / lo integran cinco provincias / lo configuran cinco provincias'; 'Greco, Visco, Canzio, Trapani, son todos napolitanos y constituyen / forman / son la flor y nata de la clase política' (véase la frase italiana en 2.2). Pero si decimos "El problema lo constituía el Papa”, o "El problema lo constituían los valdenses" (en versión copulativa "El problema era el Papa", "El problema eran los valdenses"), el sentido compositivo se pierde. Queda neutralizado, para decirlo con más exactitud, el sentido original según el cual $\mathrm{X}$ está constituido o consiste en $\mathrm{N}$ elementos, elementos que quedan reducidos a uno: si el componente es uno solo o se prescinde de todos los demás, el resultado es que $\mathrm{X}$ es $\mathrm{Y}$.

Que este sentido compositivo entra en intersección con el aparencial y el aspectual lo probaría la posibilidad de traducir pseudocopulativos con fórmulas del tipo "mostrar su 
faceta / cara / lado / imagen más", en las que lo aparencial y lo compositivo se combinan para expresar un cambio:

Loren: Con Scola mi scoprii debole [...] Sophia Loren ricorda così l'esperienza di Una giornata particolare, il film di Ettore Scola in cui l'attrice fu, per la prima volta, “una donna remissiva e sottomessa". [Loren: Con Scola descubrí mi lado débil] (Redazione 2003)

Una squadra che nel momento più importante si è dimostrata pessima e che non sarebbe arrivata fin qui se non avesse pianto perché la Spagna battesse la Croazia nella fase a gironi. [Un equipo que en el momento más importante ha mostrado su peor cara] (Todarello 2012)

Saber moverse metonímicamente en los tres territorios definirá, sin duda, una de las mayores virtudes del buen traductor. Y tomar conciencia de la importancia de estos mecanismos junto a los metafóricos no puede sino ayudarle, por consiguiente, a perfeccionar sus habilidades.

Bibliografía

Bermejo Calleja, Felisa (1994): "Verbos de cambio o devenir en español", en Salvador Montesa Peydró y Antonio Garrido Moraga (eds.): Español para extranjeros: Didáctica e investigación. Actas del Segundo Congreso Nacional de ASELE, Málaga: ASELE, págs. 47-60.

BINI, Milena y GuIL, Pura (2002): "Italiano y español: algunos puntos de contraste", Carabela, $\mathrm{n}^{\circ} 51$, págs. 69-94.

CARRERA DÍAZ, Manuel (1984): "Italiano y español: elementos para una comparación", en Joaquín Arce y otros: Italiano y español. Estudios lingüísticos, Sevilla: Universidad de Sevilla, págs. 185-219.

CARrera DíAZ, Manuel (2007): “Spagnolo e italiano: da una lingua all'altra”, en Chiara Preite y otros (eds.): Esempi di multilinguismo in Europa. Inglese lingua franca e italiano lingua straniera. La contrastività nella codificazione linguistica. XV 
Incontro del Centro Linguistico Bocconi (Università Bocconi, 25 novembre 2006), Milán: Egea, págs. 249-260.

Climent RocA, Salvador (2000): "Individuación e información Parte-Todo. Representación para el procesamiento computacional del lenguaje", Estudios de Lingüística del Español, vol. 8. Consultable en: <http://elies.rediris.es/elies8/>.

Correia Palacios, Elísabeth (2012): Alicia en el país de los verbos de cambio, Salamanca: Universidad de Salamanca. Consultable en: $<$ http://www.mecd.gob.es/dctm/redele/Material-RedEle/Biblioteca/2013-bv14/2013_BV_14_05Elisabeth-Correia.pdf?documentId=0901e72b8153cb82>.

Demonte, Violeta y Masullo, Pascual José (1999): “La predicación: Los complementos predicativos", en Ignacio Bosque y Violeta Demonte (dirs.), Gramática descriptiva de la lengua española, Madrid: Real Academia Española / Espasa Calpe, vol. 2, págs. 2461-2523.

Fernández Leborans, María Jesús (1999): "La predicación: Las oraciones copulativas”, en Ignacio Bosque y Violeta Demonte (dirs.), op. cit., vol. 2, págs. 2357-2460.

Flores ReQueJo, María José (2008): Los marcadores del discurso en el español peninsular y sus equivalencias en italiano, 1. Estructuradores de la información, conectores, reformuladores y operadores discursivos, Roma: Aracne.

GARCÍA DINI, Encarnación (1999): "Para una didáctica del español en Italia: observaciones acerca del verbo andar y su entorno", en Norbert von Prellwitz y otros (dirs.): Lo spagnolo d'oggi: forme della comunicazione, 3. Atti del XVIII Convegno dell'Associazione Ispanisti Italiani (Siena, 5-7 marzo 1998), Roma: Bulzoni / Associazione Ispanisti Italiani, págs. 195-213.

GAROSI, Linda (2010): “Oraciones pasivas en italiano y español: dificultades traductivas y análisis lingüístico contrastivo", Revista Electrónica de Lingüística Aplicada, $\mathrm{n}^{\mathrm{o}}$ 9, págs. 122-133.

GuIL, Pura (1994): "Es que... in italiano", en Anna Giacalone Ramat y Massimo Vedovelli (eds.): Italiano lingua seconda / lingua straniera. Atti del XXVI 
Congresso della Società di Linguistica Italiana (Siena, 5-7 novembre 1992), Roma: Bulzoni / Società di Linguistica Italiana, págs. 111-126.

LuQue, Rocío (2008): “Las perífrasis verbales: un planteamiento contrastivo entre español e italiano", Romanica Cracoviensia, no 8, págs. 61-69.

MARÍN GÁlVEZ, Rafael (2000): El componente aspectual de la predicación, Barcelona: Universitat Autònoma de Barcelona.

Martínez LABIANO, Carmen (2008): Los verbos de cambio: un estudio dirigido a su tratamiento específico para estudiantes germanófonos, Madrid: Universidad Antonio de Nebrija. Consultable $<$ http://www.mecd.gob.es/dctm/redele/MaterialRedEle/Biblioteca/2010_BV_11/2010_BV_11_2_trimestre/2010_BV_11_14Mart inez_Labiano.pdf?documentId=0901e72b80e19f24>.

MARTíNEZ VÁZQUEZ, Julián (2011): "Esquemas semicopulativos aspectuales de cambio episódico en producciones de alumnos de ELSE”, Gramma, vol. 22, nº 48.

Morimoto, Yuko y PAvón Lucero, María Victoria (2006): “Los verbos pseudocopulativos modales del español”, en M. Carme Junyent Figueras (dir.): Actas del VII Congreso de Lingüística General (Barcelona, 18-21 de abril de 2006), Barcelona: Universitat de Barcelona. Publicación en CD-Rom.

Morimoto, Yuko y PAVÓn LuCERo, María Victoria (2007): Los verbos pseudocopulativos del español, Madrid: Arco/Libros.

MuÑIZ, María de las Nieves (1984): "Sobre el valor temporal de la preposición española desde y de la italiana da: apuntes para una didáctica del italiano en España”, en Joaquín Arce y otros, op. cit., págs. 169-184.

Musto, Salvatore y RIPA, Valentina (2008): "Le perifrasi gerundivali in spagnolo e in italiano: uno studio contrastivo" en Lorenzo Blini y otros (eds.): Linguistica contrastiva tra italiano e lingue iberiche. Atti del XXIII Convegno dell'Associazione Ispanisti Italiani (Palermo, 6-8 ottobre 2005), Madrid: Instituto Cervantes / Associazione Ispanisti Italiani, págs. 408-427. 
NúÑEZ RoMÁn, Francisco (2009): “Diátesis pasiva en italiano y español. Apuntes para un análisis contrastivo", Language Design, n 11, págs. 79-92.

PINO, Marta (2001): "Sobre el uso de quedar, resultar y salir como auxiliares de participios pasivos", en Alexandre Veiga y María Rosa Pérez (eds.): Lengua española y estructuras gramaticales, Santiago de Compostela: Universidade de Santiago de Compostela, págs. 251-262.

Porroche BAllesteros, Margarita (1988): “Ser”, “estar” y verbos de cambio, Madrid: Arco/Libros.

Porroche Ballesteros, Margarita (1990): Aspectos de la atribución en español (Las construcciones con un atributo adjetivo que se refiere al sujeto), Zaragoza: Pórtico.

Prestigiacomo, Carla (2008): "Diventare e i verbos de cambio", en Lorenzo Blini y otros (eds.), op. cit., págs. 474-485.

Ross, Dolores (2006): "Verbi in serie: una prospettiva tipologica", en Graziano Benelli y Giampaolo Tonini (eds.): Studi in ricordo di Carmen Sánchez Montero, Trieste: Università degli Studi di Trieste, vol. II, págs. 453-465.

SÁnchez Montero, María del Carmen (1993): Perífrasis verbales en español $e$ italiano. Estudio contrastivo, Trieste: Università degli Studi di Trieste / Edizioni LINT Trieste.

SAntano Moreno, Julián (2009): De morfología y sintaxis españolas. Dos estudios interpretativos, Milán: LED Edizioni Universitarie di Lettere Economia Diritto.

Fuentes de los ejemplos

ABATE, Gianluca (2012): "Napoli esporta la migliore governance (ma importa politici e amministratori)", Corriere del Mezzogiorno. Salerno, 6 de junio, $<\mathrm{http}$ ://corrieredelmezzogiorno.corriere.it/salerno/notizie/politica/2012/6-giugno2012/napoli-esporta-migliore-governance-ma-importa-politici-amministratori201487489838.shtml>. 
AIMI, Antonio (2010): “Lambayeque, la nuova frontiera dell'archeologia peruviana. Il progetto ProdeSipán", inédito en italiano, publicado en traducción castellana con el título "Lambayeque, la nueva frontera de la arqueología peruana. El proyecto ProdeSipán”, Artes \& Culturas, s. n., págs. 100-113.

Albertocchi, Giovanni (1996): “C'era una volta un mittente... Cronache postali dall'epistolario manzoniano", Strumenti Critici, año XI, nº 2, págs. 177-202.

AlBertocChi, Giovanni (2000): “Leopardi e Manzoni nella scia del 1827”, en María de las Nieves Muñiz (ed.): Giacomo Leopardi. Poesia, pensiero, ricezione. Atti del Convegno Internazionale di Barcellona (5-7 marzo 1998), Leonforte: Insula, págs. 181-195.

AlbINI, PierLuigi (2010): "Edward Hopper. Estetica dell'inorganico", en sitio web HomoLaicus, <http://www.homolaicus.com/arte/Hopper.pdf $>$.

Alfano Antonio y BotTAI, Roberto (2005): "La gestione dei reclami: il percorso di programmazione sanitaria nella Regione Toscana", en Gedeone Baraldo y otros (eds.): Le segnalazioni degli utenti in Sanità. Dalla tutela alla partecipazione: il circolo virtuoso del reclamo, Milán: FrancoAngeli, págs. 143-150.

ALVINO, Giuseppe (2013): "Mazzarri in uscita, De Laurentis pensa a tre sostituti”, PiùEconomia.it, 13 de marzo, $<\mathrm{http}: / /$ www.piueconomia.it/NewsStampa.aspx?id_news=6354\&PRINT=SI\&kee pThis $=$ true\&TB_iframe $=$ true $\&$ height $=600 \&$ width $=800>$.

AmAdeI, Tinina (2007): L’assistente sociale allo specchio, Milán: FrancoAngeli.

ARTEMIEVA, Irina (2001): "Vicende della pittura veneta rinascimentale all'Ermitage", en Irina Artemieva y Mario Guderzo: Cinquecento veneto. Dipinti dall'Ermitage, Milán: Skira, págs. 13-46.

BACARELla, Simona y NiCOLETTI, Giulia (2010): Nuovi scenari della vitivinicoltura siciliana, Palermo: Coreras, $<$ http://www.coreras.it/Upload/allegatipubblicazioni/Nuovi_scenari_della_vitivini coltura_siciliana.pdf $>$. 
BARGIACCHI, Enzo Gualtiero (2011): "La nascita degli studi tibetani: Ippolito Desideri e Alexander Csoma de Körös”, Antologia Vieusseux, año XVII, n 51, págs. 5-31.

B.D.P. (1997): "Speed Triple, fantasia di un telaio", Corriere della Sera, 15 de mayo, pág. 44.

Bellu, Giovanni Maria (1992): "Vietati ai magistrati gli incarichi esterni", La Repubblica, 28 de noviembre, pág. 8.

BobBiO, Norberto (1957): "Giuseppe Capograssi. Cenni commemorativi”, Atti dell'Accademia delle Scienze di Torino. Classe di Scienze morali, storiche e filologiche, vol. XCI, págs. 129-143.

Bolognini, Daniele (2007): "Beato Pietro da Ruffia Sacerdote e martire", en sitio web Santi, beati e testimoni, <http://www.santiebeati.it/dettaglio/90757>.

Bonito Oliva, Achille (2005): "Numeri innamorati”, en Miguel Marcos y otros (eds.): Colección Alfonso Artiaco. Out of sight, out of mind / Fuori dalla vista, fuori di testa / Fuera de la vista, fuera de la mente, Zaragoza: Diputación Provincial de Zaragoza, págs. 82-129.

Bulgheroni, Marisa (1965): La tentazione della chimera. Charles Brockden Brown e le origini del romanzo americano, Roma: Edizioni di Storia e Letteratura.

CAMERIERO, Luigi (2008): “Storia e funzione dell'impresa pubblica: dall'IRI alle società pubbliche", en Rosanna De Nictolis y Luigi Cameriero: Le società pubbliche “in house” e miste, Milán: Giuffrè, págs. 1-28.

CAPOGRassi, Giuseppe (1979): Pensieri a Giulia, II (1920-1921), edición de Gabrio Lombardi, Milán: Giuffrè.

CAPOGRassi, Giuseppe (1981): Pensieri a Giulia, III (1922-1924), edición de Gabrio Lombardi, Milán: Giuffrè.

CAPriolo, Paola (2008): “Charpillon”, en Luca De Fusco (ed.): Lei. Cinque storie per Casanova, Venecia: Marsilio / Napoli Teatro Festival Italia, págs. 37-47.

CARDONE, Giulio (2011): "Stilista, deejay, 18 auto e tanti gol. La nuova Lazio già pazza di Cissé”, La Repubblica, 20 de agosto, pág. 51. 
CArozzi, Andrea (2013): "Sampdoria: Avanti tutta. Con il Chievo finisce 2 a 0. Salvezza sempre più vicina", Mentelocale.it, 25 de febrero, $<$ http://genova.mentelocale.it/51088-sampdoria-avanti-tutta-chievo-finisce-2-0salvezza-sempre-piu-vicina/>.

CÀrPINO, Libera (2006): "Non voltiamo le spalle ai cavalli", en sitio web Ewriters. Scrivere per essere letti, <http://www.ewriters.it/leggi.asp?W=22162>.

Casciato, Matteo (2010): Alberto, ci sei riuscito, Bloomington: Xlibris.

Cervellati, Pier Luigi (2007): "Dalla città giardino a villetopolis", inédito en italiano, publicado en traducción castellana con el título "De la ciudad jardín a «chalépolis»", en Francesco Indovina (coord.): La ciudad de baja densidad. Lógicas, gestión y contención, Barcelona: Diputació de Barcelona, págs. 185-200.

Cibrario, Benedetta (2008): “Henriette”, en Luca De Fusco (ed.), op. cit., págs. 49-62.

CIRIACHI, Fabio (2009): “Fiori di lupo", Fili d'Aquilone. Rivista d'immagini, idee e Poesia, $\mathrm{n}^{\mathrm{o}}$ 16, <http://www.filidaquilone.it/num016ciriachi.html >.

Consorzio Tutela Gorgonzola (2005): "Un formaggio al giorno... Il Gorgonzola", Notiziario Ascom, nº 73, pág. 18.

Coppola, Antonio (2010): “Editoriale”, MondoAuto, año XXVIII, nº 92, pág. 3.

CRISTIANA (2007): “Anna (2/1/1998-28/3/1998)”, Semi per la SIDS. Testimonianze, 8 de mayo, <http://www.sidsitalia.it/sostegno/anna.htm>.

DE BAC, Margherita (2008): "Trapianti, meno donatori. 9.500 in lista d'attesa", Corriere della Sera, 19 de junio, pág. 10.

De Fusco, Luca (2008): “Il Prologo”, inédito, recitado en el espectáculo Lei. Cinque storie per Casanova, Napoli Teatro Festival Italia y Teatro Stabile del Veneto (no recogido en la edición impresa).

D’ELIA, Giovanni (2013), “Il vento della recessione spazza via l'Artigianato", LeggiOggi.it, 25 de abril, <http://www.leggioggi.it/2013/04/25/1l-vento-dellarecessione-spazza-via-lartigianato/>. 
FALAPPI, Fabio (2011): "India: in arrivo il tablet low cost", News @ Home, 10 de octubre, <http://newsathome-ff.blogspot.com.es/2011_10_01_archive.html>.

Fiat Auto (1985): Fiat Uno. Uso e Manutenzione, Turín: Tip. Torinese.

FLC CGIL (2006): "Precariato nella scuola, nell'università e nella ricerca", Federazione Lavoratori della Conoscenza CGIL, 20 de noviembre, $<$ http://www.flcgil.it/files/pdf/20061120/finanziaria-2007-scheda-flc-suprecariato-scuola-universita-e-ricerca-2920482.pdf $>$.

FoschinI, Paolo (2006): “«L’ex prefetto sconfitto perché troppo di sinistra». «No, troppo poco»", Corriere della Sera, 4 de junio, pág. 5.

FREDIANI, Andrea (2012): Le grandi battaglie di Roma antica. I combattimenti e gli scontri che hanno avuto come protagonista la città eterna, Roma: Newton Compton. Primera edición: 2002.

G4BRY (2007): "Promessa d'amore eterno", en sitio web EFP. Il tuo sito di fanfiction, $<$ http://www.efpfanfic.net/viewstory.php?sid=151787\&i=1>.

Galeazzo, Patrizia (2004): “Comunicazione e scuola", en Stefano Rolando (ed.): La comunicazione di pubblica utilità 2 - Società, economia, cultura, Milán: FrancoAngeli, págs. 112-127.

Garassino, Barbara (2011): Passi fra le ombre. Scheda, Chiavari: Internòs Edizioni, $<\mathrm{http} / / / \mathrm{www} . i n t e r n o s e d i z i o n i . c o m / s c h e d a \_g a r a s s i n o \_p a s s i f r a l e o m b r e . p h p>$.

Gasparoli, Paolo y TAlamo, Cinzia (2009): Manutenzione e recupero. Criteri, metodi e strategie per l'intervento sul costruito, Florencia: Alinea. Primera edición: 2002.

GAVAZZA, Cristina (2008): "Le figure autorevoli: i padri e le madri adottive", en Franco Cambi y otros (eds.): L’immagine della società nella fiaba, Roma: Armando Editore, págs. 208-210.

Gentili, Bruno (2006): Poesia e pubblico nella Grecia antica. Da Omero al V secolo, Milán: Feltrinelli. Primera edición: Bari: Laterza, 1984.

GIBELLI, Maria Cristina (2007): "I costi economici e sociali della città a bassa densità", inédito en italiano, publicado en traducción castellana con el título "Los costes 
económicos y sociales de la ciudad de baja densidad", en Francesco Indovina (coord.), op. cit., págs. 277-306.

GIORDANO, Salvatore (2010): Il nuovo manuale delle scritture contabili, Santarcangelo di Romagna: Maggioli. Primera edición: 2004.

GonzÁlez de VegA, Javier (1996): A la sombra de Adolfo Suárez, Barcelona: Plaza \& Janés.

GranAtA, Guido (2007): Compendio di omeopatia, Milano: Hoepli. Primera edición: 1990.

Guagnano, Giacinto Davide (2008): “Al Tivoli si ride nel segno di Zelig”, La Stefani. Settimanale bolognese di inchieste e servizi, 17 de marzo, $<$ http://www.lastefani.it/settimanale/archivio08/article.php?directory $=080317 \& b 1$ ock $=5 \& \mathrm{id}=1>$.

Gurian, Roberto y De Prato, Bruno (1997): "Due modi di essere sportive. Lancia e Bmw mettono in strada vetture prestigiose", Corriere della Sera, 15 de mayo, pág. 44.

HAZAN, Maurizio (2006): La nuova assicurazione della RCA nell'era del risarcimento diretto, Milán: Giuffrè.

INDOVINA, Francesco (2007): "Presentazione: prima della città diffusa" y "Conclusione: dopo la città a bassa densità", inéditos en italiano, publicados en traducción castellana con el título "Introducción: antes de la ciudad difusa" y "Conclusión: después de la ciudad de baja densidad", en Francesco Indovina (coord.), op. cit., págs. 13-23 y 525-540.

Izzo Vitiello, Italia (2006): La casa sul fiume, Roma: Sovera Multimedia.

LeCcisotTI, Tommaso (1960): “AIGLERIO (d'Ayglier, d'Aygler), Bernardo", en Alberto Maria Ghisalberti (dir.): Dizionario biografico degli italiani, vol. I, hoy consultable en $\quad<$ http://www.treccani.it/enciclopedia/bernardoaiglerio_(Dizionario_Biografico)/>. 
Leone, Alfonso (1984): "Premessa", en Alfonso Leone y Rosa Landa: I paradigmi della flessione verbale nell'antico siciliano, Palermo: Centro di Studi Filologici e Linguistici Siciliani, págs. 9-10.

LORENZI, Sandra (2012): “Domande e risposte sulla dermatologia. Perché i miei capelli sembrano sempre sporchi?”, Oggi.it. OK Salute e benessere, 20 de febrero, $<$ http://www.ok-salute.it/consulto/idDomanda/41044>.

MaetzKe, Anna Maria (2002): "Il Volto Santo di Sansepolcro. Documentata riscoperta del più antico Crocifisso monumentale dell'Occidente", en Marina Armandi y Giuliano Centrodi (eds.): La bellezza del sacro. Sculture medievali policrome. Catalogo della mostra (Arezzo, settembre 2002 - febbraio 2003), Florencia: Nuova Grafica Fiorentina, págs. 1-13.

MARI, Alessandro (2011): Troppo umana speranza, Milán: Feltrinelli.

MARiMALFOY (2012): "Like an Extra", en sitio web EFP. Il tuo sito di fanfiction, $<$ http://www.efpfanfic.net/viewstory.php?sid=946171 $>$.

MARMUGI, Claudio (2011): “Cambia gestore a sua insaputa: deve pagare”, Il Tirreno.

Livorno, 7 de diciembre, $<$ http://iltirreno.gelocal.it/livorno/cronaca/2011/12/07/news/cambia-gestore-a-suainsaputa-deve-pagare-1.2896365>.

MARrÈ, Davide (2008): “Tradizione Romana”, en Davide Marrè (ed.): L'essenza del Neopaganesimo, Milán: Circolo dei Trivi, págs. 35-37.

MeAle, Gaetano (1922): Positiva scienza di governo per parlare di politica senza vecchie ciurmerie e asinerie, Turín: Fratelli Bocca.

Menaldo, Carla (2008): “M.M.”, en Luca De Fusco (ed.), op. cit., págs. 21-35.

Meneguzzo, Marco (2005): “La forma restituita”, en Marco Meneguzzo (ed.): “La forma restituita”, arte italiano de fin de milenio, Palma de Mallorca: Centre Cultural Contemporani Pelaires, págs. 9-12.

MonaCo, Francesco (2011): “Assessore, ci consenta una richiesta”, Tribuna Libera, 15 de octubre, <http://tribunalibera.blogspot.com.es/2011/10/assessore-ci-consentauna-richiesta.html>. 
OsPedale Buccheri LA Ferla (2002): “Linee guida per l'anestesia in Ostetricia”, en sitio web Anestit, <http://anestit.unipa.it/pazienti/textost.htm>.

Ottomano, Vincenzina C. (2006): “Don Carlos. Il contesto", inédito en italiano, publicado en traducción catalana con el título "Don Carlos. El context", en Rosa Samaranch y Anna Casa (eds.): Temporada d'Òpera 2006-2007, Barcelona: Amics del Liceu, págs. 73-75.

PAOLILlo, Francesco (2004): "MOTO GUZZI V11 Cafè Sport vs DUCATI Monster 1000 Dark i.e.", Moto.it, 28 de agosto, <http://www.moto.it/prove/prova4709asp4709.html>.

PARAVIDINO, Fausto (2001): Noccioline (Nuts), <http://www.provinz.bz.it/intendenzascolastica/download/peanuts_copione.pdf $>$.

Pasolini, Pier Paolo (1991): Le regole di un'illusione. I film, il cinema, edición de Laura Betti y Michele Gulinucci, Roma: Associazione "Fondo Pier Paolo Pasolini”. Primera edición del fragmento citado: Gideon Bachmann y Donata Gallo: “Conversazione con Pier Paolo Pasolini”, Filmcritica, vol. XXVI, nº 256, agosto de 1975, págs. 235-239.

Pentagallo, Stefano y De Gaspari, Luca (2013): “Djokovic, $4+8$ fa 12. Federer spreca 3 match point", Quotidiano.Net. UbiTennis, 2 de marzo, $<$ http://www.ubitennis.com/sport/tennis/2013/03/01/852656-djokovic.shtml>.

Perrini, Matteo (2000): “Lettera 2750. Erasmo da Rotterdam a Johann Faber, vescovo di Vienna. Introduzione", en Erasmo da Rotterdam: Ritratti di Thomas More, edición de Matteo Perrini, Brescia: La Scuola Editrice, consultable en: $<$ http://www.ccdc.it/DettaglioDocumento.asp?IdDocumento=1343\&IdCategoria= $15 \& \operatorname{Id}$ Autore $=\& \operatorname{IdArgomento}=\&$ testo $=\& \mathrm{Id}=3>$.

PolimenI, Davide (2011): Il canto dell'angelo, Trento: UNI Service.

REDAZIONE (2003): "Loren: Con Scola mi scoprii debole", Tgcom Spettacolo, 9 de junio,

$<$ http://www.tgcom24.mediaset.it/spettacolo/articoli/articolo127961.shtml $>$. 
REDAZIONE (2009): "Internet diventa utile anche contro l'insonnia”, Città di Genova, 1 de junio, $<$ http://www.cittadigenova.com/Italia-Mondo/Internet-diventa-utileanche-contro-1-7265.aspx>.

Redazione (2010): “Gs Capriatese 1968. Pagellone 2009/2010”, Calcio Campano, 5 de junio,

$<$ http://calciocampano.forumcommunity.net/?t=38029243\#entry266944227>.

REDAZIONE (2013): “comScore: dati USA su social network e advertising", Tech Economy, 4 de marzo, <http://www.techeconomy.it/2013/03/04/comscore-datiusa-su-social-network-e-advertising/> .

RigANO, Valentina (2005): In punta di piedi, Turín: L'Ambaradan.

RoCCHI, Andrea (2011): “L'esercito multi-etnico di Annibale Barca nella seconda guerra punica", Tutto Storia, 1 de febrero,

$<\mathrm{http}$ //www.tuttostoria.net/focus_recensione_storia_antica.aspx?ID=496>.

Russo, Dario (2013): “Costume e società - Capitolo IV”, BuonGiornoSicilia, 16 de enero,

$<$ http://www.buongiornosicilia.it/rubriche/narrativa_egrave/costume_e_societa__capitolo_iv-790>.

SCAPPARONE, Paolo (1998): "Sulla definizione economica delle specie dei beni", Economia Politica, año XV, nº 2, págs. 219-240.

SEMINARA, Graziella (2006): "La redenzione di Norma", inédito en italiano, publicado en traducción catalana con el título "La redempció de Norma", en Rosa Samaranch y Anna Casa (eds.), op. cit., págs. 192-196.

Senato Della Repubblica (2012): Atti parlamentari. XIV Legislatura - Disegni di legge e relazioni - Documenti, $\mathrm{n}^{\circ} 1713,11$ de septiembre.

SENSI, Mario (1995): Storie di bizzoche tra Umbria e Marche, Roma: Edizioni di Storia e Letteratura.

SORRENTINO, Andrea (2011): "Difesa Gasperini. «Ma quali dubbi. Inter da scudetto»", La Repubblica, 20 de agosto, págs. 50-51.

SpAZIANI, Maria Luisa (2008): "Lucrezia”, en Luca De Fusco (ed.), op. cit., págs. 63-77. 
TODAREllo, Marco (2012): "Il triplete che risolleva Madrid", Lettera 43, 2 de julio, $<$ http://www.lettera43.it/fatti/il-triplete-che-risolleva-madrid_4367556347.htm>.

VenezIA, Mariolina (2008): “Lia”, en Luca De Fusco (ed.), op. cit., págs. 79-89.

VITTA, Fabiana (2013): "Descrizione della bruschetta", ComeQuando.it, 7 de marzo, $<$ http://www.comequando.it/descrizione-della-bruschetta/ $>$.

Zamagni, Stefano (2008): L'economia del bene comune, Roma: Città Nuova Editrice. Primera edición: 2007.

Recibido: 3 de julio de 2013 Aceptado: 24 de noviembre de 2014 Revisado: 1 de diciembre de 2014 Publicado: 4 de diciembre de 2014 Actualizado: 18 de diciembre de 2014 